\title{
A novel split-reflux policy in batch reactive distillation for the optimum synthesis of a number of methyl esters
}

\author{
Dhia Y. Aqar ${ }^{1}$, Nejat Rahmanian ${ }^{2}$, Iqbal M. Mujtaba ${ }^{2,3}$ \\ ${ }^{1}$ Ministry of Oil, Office of Ministry Advisor for Oil and Gas Supplies, Baghdad, Iraq \\ ${ }^{2}$ Chemical Engineering Division, School of Engineering, University of Bradford, Bradford, BD7 1DP, UK \\ ${ }^{3}$ Corresponding author I.M.Mujtaba@bradford.ac.uk
}

\begin{abstract}
The production of a number of methyl esters such as methyl decanoate (MeDC), methyl salicylate (MeSC), and methyl benzoate (MeBZ) by esterification reactions of several carboxylic acids such as decanoic acid (DeC), salicylic acid (ScA), and benzoic acid (BeZ) with methanol, respectively, through a reactive distillation system (batch or continuous) is cost-intensive and operationally challenging operation. It is difficult to keep the reaction species together in the reaction section due to wide boiling point differences between the reactants. Methanol (in those esterification processes) having the lowest boiling temperature in the reaction mixture can separate easily from carboxylic acid as the distillation progresses, resulting in a severe drop in the reaction conversion ratio of the acid employing batch/continuous distillation system. In order to overcome this type of challenge and to increase the overall reaction conversion, a novel split-reflux conventional batch reactive distillation configuration (sr-BRD) is proposed/studied in detail in this investigation.

The optimal performance of $\mathrm{BRD} / \mathrm{sr}-\mathrm{BRD}$ column is determined in terms of maximum achievable conversion of acids, and highest concentration of the esters produced for each chemical reaction scheme. The results for given separation tasks are compared with those obtained using conventional batch distillation (BRD) process. The optimization results clearly show that the sr-BRD process significantly improves the process efficiency, the conversion ratio of acid, and the product purity of methyl esters compared to that obtained via the BRD process.
\end{abstract}

Keywords: BRD; sr-BRD; Chemical Reaction; Modelling; Optimization; Batch Time, Product Purity 


\section{Introduction}

The alkyl esters produced from the esterification reactions are commonly used in many industrial such as resin cleaners, heavy duty hand cleaners, gear and rolling oils, plasticizers in polymer industries, flavors, plastics, green solvents, perfumes, and pharmaceutical and food industries (Lamba et al., 2018). Reactive distillation technology is becoming more commonly used in industry as a way to increase productivity, decrease energy demand, and total capital cost. The operation of batch column may be more flexible and appropriate than continuous distillation column for small scale production, high added value specialty and fine chemicals, and provides some benefits such as lower investment cost, easier start-up and shutdown phase. The combination of chemical reaction and distillation in the single shell (known as batch reactive distillation system) would be more suitable when one of the products being the less volatile component in the reaction mixture. It allows integration of the benefit of both reactive distillation and batch operation, which can lead to enhance the conversion rate of acid.

The esterification reactions of decanoic, and salicylic acids with methanol to synthesize methyl alkyl esters are common practices in the chemical and petrochemical industries. For instance, the production of methyl decanoate by the esterification reaction of decanoic acid and methanol employing a continuous reactive distillation process was considered only by few scholars (Steinigeweg and Gmehling, 2003; Machado et al., 2011). Recently, Lamba et al. (2018) produced methyl decanoate in a small batch reactor through the esterification reaction of decanoic acid with methanol on solid acid catalyst (Amberlyst-15) utilizing EleyRideal (ER) model. More recently, the formation of methyl decanoate was investigated in detail employing different kinds of batch reactive configurations in our recent work (Aqar et al., 2017a; 2017c; 2018a). The esterification process of salicylic acid (ScA) with methanol $(\mathrm{MeOH})$ producing methyl salicylate $(\mathrm{MeSC})$ was conducted in the past by a number of 
scholars (Bochner et al., 1965; Chandavasu, 1997; D'Souza and Nagaraju, 2007; and Shi et al., 2010). Bochner et al. (1965) studied experimentally the esterification of salicylic acid with methanol over an ion exchange resin-catalyzed using a vapor phase chromatography. They developed a Langmuir-Hinshelwood model for a kinetic expression. Chandavasu (1997) developed a model for the esterification of salicylic acid with methanol in the presence of a homogeneous catalyst using a coupling of the pervaporation unit with the chemical reactor. More recently, Pečar and Goršek (2018) studied the kinetic esterification of benzoic acid with methanol to synthesize methyl benzoate using two different sorts of acid catalysts $\left(\mathrm{S}_{1}\right.$ and $\left.\mathrm{S}_{3}\right)$ in batch reactor system. They found out that a maximum conversion level of benzoic acid of $60 \%$ was achieved using the catalyst $S_{1}$ compared to that obtained using the catalyst $S_{3}$.

The paper studies a new split-reflux strategy in batch reactive distillation (sr-BRD) for the production of different methyl esters (MeDC, MeSC, and MeBZ). The suggested strategy recycles methanol back to the carboxylic acid with which it reacts to improve the reaction conversion and thus the product purity. Also, in this work, the performance of a novel splitreflux batch reactive distillation process (sr-BRD) has been compared with the regular batch reactive distillation process (BRD) with excess and equimolar feed cases in terms of maximum product composition, and the reaction conversion using a rigorous model based on unsteady state mass and energy balances built in gPROMS (general Process Modeling System, 2017) software.

Note, Aqar et al. (2016b) studied two other novel batch reactive configurations namely integrated conventional batch distillation (i-CBD) and integrated semi-batch distillation (iSBD) columns. Although the comparison of the proposed sr-BRD configuration with i-CBD and i-SBD configurations are beyond the scope of this study, it will be worth noting the qualitative difference between these configurations. In i-CBD, the alcohol (methanol) being 
recycled will have cumulative effect due to the accumulator tank while in sr-BRD it will not have such effect. Therefore, the quality (i.e. composition) of alcohol being recycled in both cases will be different and therefore will have impact on reaction and separation. In i-SBD, alcohol together with other species are accumulated over a period of time and then alcohol is separated and is recycled to the next batch. Therefore, the recycle of alcohol is discrete and not continuous as in the case of i-CBD and i-SBD and therefore will have impact on reaction and separation.

In this work, three different case studies (MeDC, MeSC, and MeBZ) by esterification reactions of several carboxylic acids of decanoic acid (DeC), salicylic acid (ScA), and benzoic acid (BeZ) with methanol) are considered to demonstrate the applicability of proposed batch configuration (sr-BRD). However, to best of authors' knowledge, the use of different types of batch reactive distillation columns for the productions of both MeSC, and MeBZ is non-existent. Both the total quantity in the still and the product concentration are utilized as the operating constraints. Reflux ratio for BRD mode and both reflux ratio and reflux side rate for sr-BRD mode are treated as optimization variables and are considered as piece-wise constant parameters. The dynamic optimization problem is converted to a nonlinear programming (NLP) problem, which is solved by using Control Vector Parameterization (CVP) method using successive quadratic programming (SQP) technique within gPROMS software (more details about this technique can be found in Mujtaba, 2004).

\section{Column Configuration and Process Modelling}

\subsection{Conventional batch distillation process (BRD)}

The model equations, in terms of mass and energy balances, thermodynamics and chemical kinetics, for BRD, and sr- BRD (Figure 1), results in a system of differential and differential algebraic equations (DAEs). Note, that reaction occurs in the condenser drum, in all column plates and in the reboiler tank for both column configurations. The model is an equality 
constraint. The BRD column (Figure 1a) model is same as that presented in Aqar et al (2016a, 2017b) except that the reaction kinetics and phase equilibria for both DeC, ScA, and BeZ esterification reactions. Different levels of simplifying assumptions are typically made for the process models such as the vapour holdups and column hydraulics are negligible, and ideal vapour liquid equilibrium is assumed. Also, constant operating pressure and constant molar overflow are assumed.

\subsection{The split-reflux batch reactive distillation system (sr-BRD)}

The reflux rate from the condenser drum is split into two parts (reflux rate 1 and 2) in this batch system, where the flow rate 1 refluxed back into the first stage of the distillation column (similar to BRD), and the flow rate 2 goes into the pot drum as the process continues (Figure 1b). The reason for splitting the reflux and feeding into the pot drum will be clearer in section 4.1. The process model of sr-BRD mode is most similar to the BRD mode but with the extra equations accounting for reflux 2. Note, the detailed dynamic models for both (BRD, sr-BRD) configurations are presented in Appendix A. 


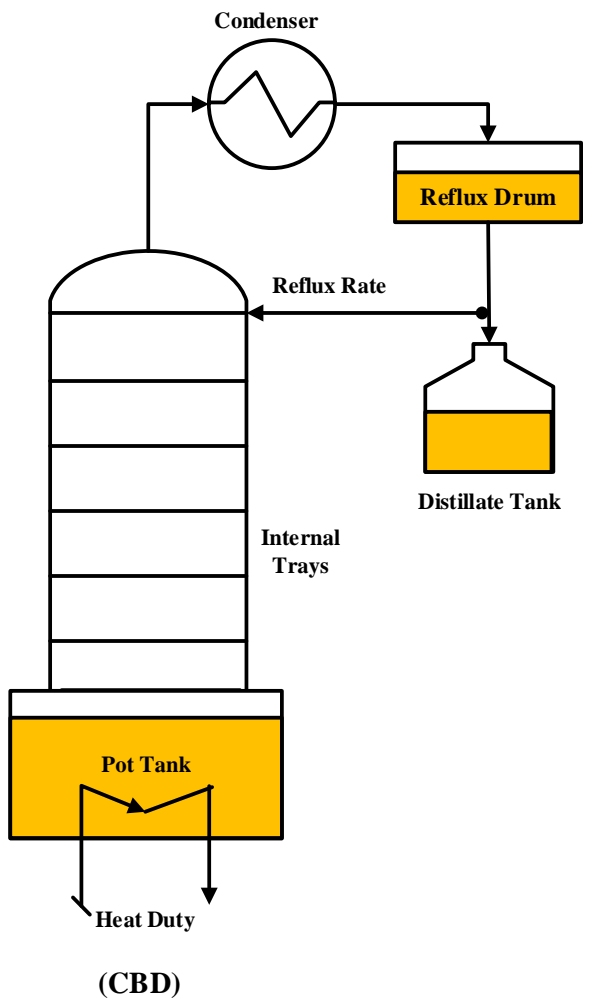

(BRD)

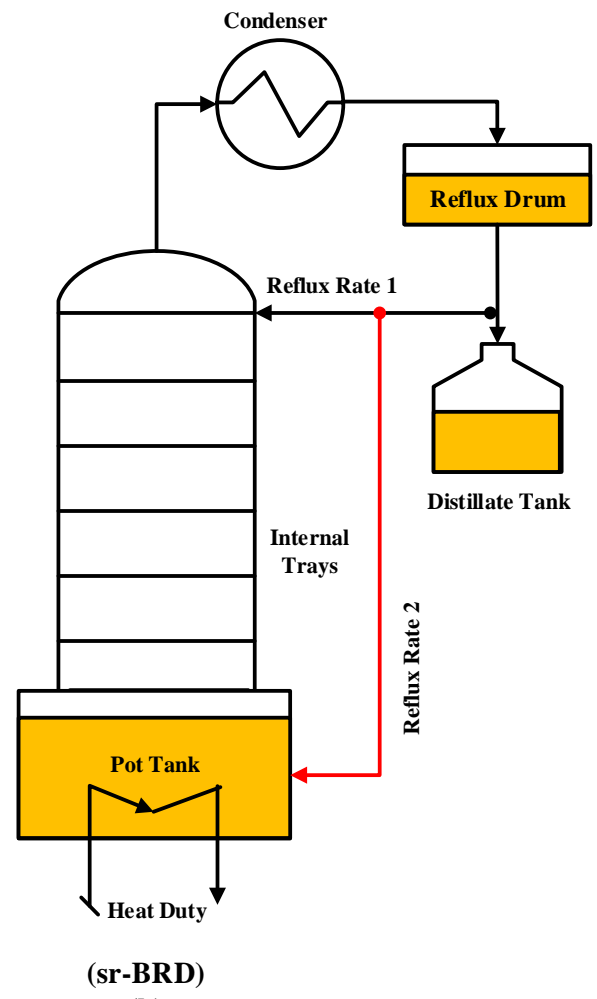

(b)

Figure 1: Schematic diagram of two batch configurations: (a) conventional (BRD) and (b) split-reflux conventional batch distillation systems (sr-BRD).

\subsection{Reaction kinetics and phase equilibria (VLE)}

Three different chemical reactions are studied in this work as summarized in Table 1. Boiling points of each chemical component are shown in brackets.

Table 1: Chemical Reactions together with the Boiling Points for Three Reaction Schemes

\section{Methyl Decanoate (MeDC) System}

$\mathrm{DeC}(543.15)+\mathrm{MeOH}(337.85)<=\mathrm{MeDC}(505.13)+\mathrm{H}_{2} \mathrm{O}(373.15)$

$\begin{array}{lllll}\text { C.O. } & 4 & 1 & 3 & 2\end{array}$

\section{Methyl Salicylate (MeSC) System}

$\mathrm{ScA}(529.00)+\mathrm{MeOH}(337.85) \Leftrightarrow=\mathrm{MeSC}(493.65)+\mathrm{H}_{2} \mathrm{O}(373.15)$
C.O. 4
1
3 


\section{Methyl Benzoate (MeBZ) System}

$$
\mathrm{BeZ}(523.00)+\mathrm{MeOH}(337.85)<=>\mathrm{MeBZ}(472.65)+\mathrm{H}_{2} \mathrm{O}(373.15)
$$
C.O. 4
1
3

$*$ C.O. $=$ Component order in each reaction in terms of boiling points

\subsubsection{The esterification reaction of decanoic acid}

Steinigeweg and Gmehling (2003) explored experimentally the modified kinetic model (LHHW) for the formation and hydrolysis of methyl decanoate (MeDC). MeDC was formed due to chemical reaction between decanoic acid with methanol over the heterogeneous catalyst (Amberlyst-15) via the reversible reaction scheme is expressed by in Equation 1. Note, the vapour liquid equilibrium (VLE) model for the MeDC system were taken from our previous work (Aqar et al., 2017a).

$-\mathrm{r}_{\mathrm{DeC}}=\mathrm{m}_{\text {cat }}\left\{\frac{3.1819 \times 10^{6} \exp \left(\frac{-72230}{\mathrm{RT}}\right) \mathrm{a}_{\mathrm{DeC}} \mathrm{a}_{\mathrm{MeOH}}}{\left(2.766 \mathrm{a}_{\mathrm{H}_{2} \mathrm{O}}\right)^{2}}-\frac{3.5505 \times 10^{5} \exp \left(\frac{-71900}{\mathrm{RT}}\right) \mathrm{a}_{\mathrm{MeDC}}}{\left(2.766 \mathrm{a}_{\mathrm{H}_{2} \mathrm{O}}\right)}\right\}$

\subsubsection{The esterification reaction of salicylic acid}

The reversible reaction system for esterification of salicylic acid $(\mathrm{ScA})$ and methanol $(\mathrm{MeOH})$ to produce methyl salicylate $(\mathrm{MeSC})$ and water $\left(\mathrm{H}_{2} \mathrm{O}\right)$ is explored in detail by Chandavasu (1997). Kinetic equation of catalytic synthesis of MeSC catalyzed by the cation exchange resin (Dowex 50) catalyst is expressed by Equation (2), which is taken from (Chandavasu, 1997).

$-\mathrm{r}_{\mathrm{ScA}}=\mathrm{m}_{\mathrm{cat}} \times 2.67 \times 10^{19} \exp \left(\frac{-16248.5}{\mathrm{~T}}\right)\left\{\mathrm{C}_{\mathrm{ScA}} \mathrm{C}_{\mathrm{MeOH}}-36.85 \times 10^{10} \exp \left(\frac{-7797.7}{\mathrm{~T}}\right) \mathrm{C}_{\mathrm{MeSC}} \mathrm{C}_{\mathrm{H} 2 \mathrm{O}}\right\}$

\subsubsection{The esterification reaction of benzoic acid}

The reversible reaction system for esterification of benzoic acid $(\mathrm{BeZ})$ and methanol $(\mathrm{MeOH})$ to form methyl benzoate $(\mathrm{MeBZ})$ and water $\left(\mathrm{H}_{2} \mathrm{O}\right)$ is investigated by Pečar and Goršek 
(2018). Kinetic modeling of catalytic synthesis of MeBZ catalyzed by functionalized silica gel catalyst is expressed by Equation (3), which is taken from (Pečar and Goršek, 2018).

$-\mathrm{r}_{\mathrm{BeZ}}=\mathrm{m}_{\mathrm{cat}}\left\{6.00 \times 10^{5} \exp \left(\frac{-5400.53}{\mathrm{~T}}\right) \times \mathrm{C}_{\mathrm{BeZ}}\right\}$

Note, all the kinetic models are catalyst loading $\left(\mathrm{m}_{\mathrm{cat}}\right)$ based. For both MeSC and MeBZ systems, the binary interaction parameters of the NRTL method were taken from the data bank of Aspen Plus (Table B.1) and the Antoine constants (Table B.2) were taken from Yaws (1997) in Appendix B. It was stated in Ullmann's Encyclopedia (2014) that a zeotrope was formed in binary mixture (methyl benzoate + water) for the esterification reaction of benzoic acid and methanol. However, according to DeGarmo et al. (1992), the solubility of acids in the mixture and the formation of azeotrope in reactive distillation column is commonly overcome due to its capability to increase the conversion ratio of carboxylic acids by removing the products instantaneously from the reactive zone, and by eliminating the azeotrope forming elements in reaction (DeGarmo et al., 1992). Perhaps, this could be the main reason why the solubility between the reactants and the azeotrope formation were not taken into account by a number of scholars in their study (Chandavasu, 1997; Steinigeweg and Gmehling, 2003; Machado et al., 2011; and Pečar and Goršek, 2018). Based on these observations, we have decided not to consider solubility of acids and azeotropes in this work.

\section{Dynamic optimization problem framework}

In the present study, the performance of both column systems (BRD, sr-BRD) is measured in terms of minimum batch time for a given total amount in the reboiler and the desired product composition. The optimization problems can be described as follows:

\subsection{Minimum Batch Time Problem}

Mathematically, the optimization problem (OP) can be represented as follows:

OP

$$
\begin{aligned}
& \text { Min } \quad t_{F} \\
& \mathrm{R}_{\mathrm{BRD}}(\mathrm{t})
\end{aligned}
$$

(For BRD) 


$$
\begin{gathered}
\text { Or } \\
\mathrm{R}_{\mathrm{sr}-\mathrm{BRD}}(\mathrm{t}), \mathrm{L}_{\mathrm{S}}
\end{gathered}
$$

S. t. :

$$
\begin{aligned}
& \mathrm{f}\left(\mathrm{t}, \frac{d x}{d t}, \mathrm{x}, \mathrm{u}, \mathrm{v}\right)=0 ; \quad\left[\begin{array}{ll}
0 & \mathrm{t}_{\mathrm{F}}
\end{array}\right] \quad \text { (DAE process model, inequality constraints) } \\
& \mathrm{B}_{\operatorname{Pr}}=\mathrm{B}_{\operatorname{Pr}}^{*}+\varepsilon \quad \text { (Inequality Constraints) } \\
& \mathrm{x}_{\mathrm{Pr}}=\mathrm{x}_{\mathrm{Pr}}^{*}+\varepsilon \quad \text { (Inequality Constraints) }
\end{aligned}
$$

$\mathrm{B}_{\mathrm{Pr}}$, and $\mathrm{x}_{\mathrm{Pr}}$ are the quantity of bottom product and concentration of ester product at final batch time $\left(\mathrm{t}_{\mathrm{F}}\right)$ in the pot drum, (denotes that the $\mathrm{B}_{\mathrm{Pr}}^{*}$ and $\mathrm{x}_{\mathrm{Pr}}^{*}$ are specified). $\mathrm{R}_{\mathrm{BRD}}$ and $\mathrm{R}_{\text {sr-BRD }}$ are the optimum reflux ratios; $\mathrm{L}_{\mathrm{S}}$ is the reflux side rate profile (for the sr-BRD column), which are optimized into the optimization problem case and $\varepsilon$ is small positive numbering in the order of magnitude of $10^{-3}$. The process models act as inequality constraints to the dynamic optimization problem.

\section{The formation of methyl esters via the esterification operations}

\subsection{Operational Challenge}

MeDC is formed by the esterification operation of decanoic acid and methanol. Methyl Salicylate (MeSC) is synthesized via esterification salicylic acid and methanol. On other hand, methyl benzoate (MeBZ) is produced from esterification benzoic acid and methanol.

With the distillation in progress in three reaction schemes (in a reactive distillation mode), methanol (one of the reaction components) having the lowest boiling point among all the components (Table 1) in the reaction mixture will separate itself from the other reactants (acid) thus causing operational challenge. And consequently, the conversion level of the carboxylic acid to the main product (methyl ester) will be quite restricted. The boiling temperatures of the carboxylic acids (decanoic, salicylic, and benzoic acids) are the highest in the reaction mixture and therefore will stay in the reboiler drum most of the time. Therefore, it is expected that refluxing side rate (reflux 2) to the reboiler (in sr-BRD operation) will bring methanol (from the methanol rich reflux rate) and will enhance the reaction between 
methanol and acids and thus will increase the conversion of acid. However, the severity of this operational challenge will depend upon the differences in the boiling point temperature of methanol with the rest of the chemical species in the reaction mixture or on the relative volatility of the methanol in the mixture. Note, the relative volatility of methanol in MeDC scheme will be higher than those of the MeSC and MeBZ schemes if the relative volatility in those systems is based on the heaviest component in the mixture. Therefore, operationally the MeDC system will offer more operational challenge compared to MeSC and MeBZ systems. Also note, the separation of water (the second lightest component) from the reaction system (especially from ester - component 3) as the distillation continues will also be challenging affecting the methanol purity in the reflux rate and will influence the overall performance of the column. With respect to the difference in boiling point temperature of compound 2 and 3 , the MeBZ scheme will offer less challenge as compared to MeSC and MeDC schemes. Hence, the difficulty of separating water is in inverse order of the challenge of retaining methanol with the acids. These are all qualitative expectations from the point of view of boiling temperatures of the reaction components. The ultimate behavior of the reaction system will be based on the reaction model and thermodynamic aspect of each system.

\subsection{The problem descriptions}

The case studies are carried out in a 10-theoretical stages distillation process (including total condenser and reboiler drum). The vapour load to the condenser was specified to be 2.5 $\mathrm{kmol} / \mathrm{h}$. Batch distillation commonly operates using one of the specific column operation modes (Mujtaba, 2004): (A) constant condenser vapor load rate, (B) constant reboiler heat duty, (C) constant vapor boil-up rate and (D) constant distillate rate. In this work, the constant condenser vapour load (Mode C) is considered to operate both BRD and sr-BRD columns. In this strategy, the reboiler heat duty $\left(\mathrm{Q}_{\mathrm{r}}\right)$ gradually changes with time to maintain the constancy of the vapour rate to the reflux drum. Note, also, this operation mode is extensively 
used by a number of researchers in the past (Nad and Spigel, 1987; Wajge and Reklaitis, 1999; Edreder et al., 2011; Kao and Ward, 2014a; Kao and Ward, 2014b; Kao and Ward, 2015a; Kao and Ward, 2015b; and Aqar et al., 2018b).

The constancy of vapour load to the overhead column was maintained in the reactive column by running the column at constant approximations reflux ratio and making an energy balance around the reflux drum with suitable control tools to regulate the heat provided to the pot still (Nad and Spigel, 1987). The column trays are numbered from the top to bottom with the reflux drum as stage 1 and the still pot as the last stage. Five kmol of fresh feed loaded into the pot drum at the beginning of the process. The feed concentrations for both the excess feed and the equimolar feed ratios for three reaction systems considered in this work are documented in Table 2. The total column holdup amounts to $4 \%$ of the total initial feed charge to batch column $(5 \mathrm{kmol})$. Half of the total column holdup is placed in the reflux drum and the rest is equally distributed in the column trays. Note, the same strategy is applied for the catalyst loading distribution for both (BRD and sr-BRD) columns (Aqar et al, 2016a, b, c, 2017a, c, 2018b).

Table 2: Feed compositions for Three Reaction Schemes

\section{Methyl Decanoate (MeDC) System}

Excess Feed Case

$\left.<\mathrm{DeC}, \mathrm{MeOH}, \mathrm{MeDC}, \mathrm{H}_{2} \mathrm{O}\right\rangle$ is: $\langle 0.47,0.53,0.0,0.0\rangle$

Equimolar Feed Case

$\left.<\mathrm{DeC}, \mathrm{MeOH}, \mathrm{MeDC}, \mathrm{H}_{2} \mathrm{O}\right\rangle$ is: $\langle 0.5,0.5,0.0,0.0\rangle$

Methyl Salicylate (MeSC) System 
Excess Feed Case

$\left.<\mathrm{ScA}, \mathrm{MeOH}, \mathrm{MeSC}, \mathrm{H}_{2} \mathrm{O}\right\rangle$ is: $\langle 0.47,0.53,0.0,0.0\rangle$

Equimolar Feed Case

< $\left.\mathrm{ScA}, \mathrm{MeOH}, \mathrm{MeSC}, \mathrm{H}_{2} \mathrm{O}\right\rangle$ is: $\langle 0.5,0.5,0.0,0.0\rangle$

\section{Methyl Benzoate (MeBZ) System}

Excess Feed Case

$\left.<\mathrm{BeZ}, \mathrm{MeOH}, \mathrm{MeBZ}, \mathrm{H}_{2} \mathrm{O}\right\rangle$ is: $\langle 0.47,0.53,0.0,0.0\rangle$

Equimolar Feed Case

$\left.<\mathrm{BeZ}, \mathrm{MeOH}, \mathrm{MeBZ}, \mathrm{H}_{2} \mathrm{O}\right\rangle$ is: $\langle 0.5,0.5,0.0,0.0\rangle$

\subsection{Results and Discussions}

\subsubsection{BRD operation with excess methanol}

Excess $\mathrm{MeOH}$ in the initial feed to reboiler is used as it is the lightest boiling point compound in the reaction mixture. The optimum process for BRD mode in terms of optimal reflux ratio, final batch time, and conversion level of acids are presented in Table 3 for different product qualities and for different reaction systems.

For both MeDC and MeBZ systems as the bottom product purity increases, reflux ratio and operating batch time rise gradually, whereas, the optimum reflux ratio values, and the production batch times decrease progressively with the bottom product purity for MeSC scheme.

Note also, an increase in the bottom product concentrations of produced esters caused a highest reachable conversion ratio of acid. As far as product purity is concerned, it was not possible to achieve beyond 0.555 mole fraction (for MeDC system), 0.770 mole fraction (for MeSC system), and 0.740 mole fraction (for MeBZ system), and the maximum achievable 
conversion of carboxylic acid employing a BRD column was $62.95 \%$ for MeDC, $86.30 \%$ for MeSC, and $82.80 \%$ for MeBZ. This is due to a fast separation of methanol from the pot drum (because of the wide gap in boiling point temperatures of reaction reactants and the reverse reaction being active).

As described earlier, MeSC reaction scheme offers less challenge in terms of keeping the reactants together in the reaction zone and makes the separation of water from methyl ester slightly easier compared to MeBZ system. Thus, the BRD operation operated at a lower reflux mode and lower processing batch time to remove large amount of water from the distillation column and thus enhance the bottom product purity shifting the reaction forward. The reason for this decrease in the reflux ratio for this system is that the BRD column is trying to get rid of methanol and water quicker and in a large volume was removed from the reboiler drum to the distillate tank to meet the product purity specification thus pushing the reaction more forward. Although, methanol is the lightest, it will also be removed with water, but due to excess methanol being used, the remaining methanol in the reboiler is sufficient to convert more of the benzoic acid and thus improves the concentration of the desired product (methyl benzoate).

On the other hand, MeBZ reaction scheme offers more challenge in terms of retaining the chemical species together in the bottom tank of the distillation column and makes the separation of water from methyl benzoate more difficult. Thus, it operated at higher reflux ratio and more operating batch time to convert more acid and to increase the product purity of methyl esters (by removing water). Also, it can be realized that the difference of the boiling point temperatures between $\mathrm{MeSC}$ and $\mathrm{H}_{2} \mathrm{O}$ system $(120.50 \mathrm{~K})$ is larger than that between MeBZ and $\mathrm{H}_{2} \mathrm{O}$ system ( $\left.99.50 \mathrm{~K}\right)$.

Hence, the separation of water from methyl salicylate is much faster and easier than the separation of water from methyl benzoate. Therefore, MeSC system offers much better 
performance than MeBZ system in terms of higher conversion rate of acid and lower batch time to satisfy the desired product considerations. It can be seen from Table 3 that the decrease of reflux ratio with increasing product composition at the MeSC system assists the removal of water as it is being formed and thus shifting the chemical reaction more forward. However, methanol will also be separated with water as the lightest component. Also, the remaining of methanol in the pot drum is adequate to convert more of the salicylic acid thus increases the product concentration (methyl salicylate) due to the excess methanol in the feed mixture being utilized.

Table 3: Summary of optimization results for the three reaction systems for BRD column with excess methanol

\begin{tabular}{|c|c|c|c|}
\hline $\begin{array}{l}\text { Product Purity } \\
(\mathrm{kmol} \%)\end{array}$ & $\begin{array}{l}\text { Optimal Reflux } \\
\text { Ratio, } \mathrm{R}_{\mathrm{BRD}}(---)\end{array}$ & $\begin{array}{l}\text { Final Batch } \\
\text { time, } t_{F},(h)\end{array}$ & $\begin{array}{c}\text { Conversion of } \\
\text { Acid (\%) }\end{array}$ \\
\hline \multicolumn{4}{|c|}{ Methyl Decanoate (MeDC) System } \\
\hline 0.535 & 0.757 & 3.78 & 60.82 \\
\hline 0.545 & 0.808 & 4.79 & 61.88 \\
\hline 0.555 & 0.861 & 6.63 & 62.95 \\
\hline 0.565 & $--^{\mathrm{a}}$ & $--^{\mathrm{a}}$ & $--^{\mathrm{a}}$ \\
\hline \multicolumn{4}{|c|}{ Methyl Salicylate (MeSC) System } \\
\hline 0.755 & 0.443 & 1.65 & 84.52 \\
\hline 0.765 & 0.340 & 1.39 & 85.66 \\
\hline 0.770 & 0.265 & 1.25 & 86.30 \\
\hline 0.775 & $--^{a}$ & $--^{\mathrm{a}}$ & $--^{a}$ \\
\hline \multicolumn{4}{|c|}{ Methyl Benzoate (MeBZ) System } \\
\hline 0.725 & 0.859 & 6.52 & 81.23 \\
\hline 0.735 & 0.863 & 6.73 & 82.28 \\
\hline 0.740 & 0.866 & 6.85 & 82.80 \\
\hline
\end{tabular}




\begin{tabular}{rrrr}
0.745 & $--^{\mathrm{a}}$ & --- $^{\mathrm{a}}$ & --- $^{\mathrm{a}}$ \\
\hline${ }^{\mathrm{a}}$ Infeasible. & &
\end{tabular}

\subsubsection{The performance of BRD process with the equimolar feed case}

Here the effect of equimolar reactant ratio on the overall performance of reactive distillation for all reaction systems is investigated. The results are summarised in Table 4, including the optimal reflux ratio, and minimum operating time, and the highest conversion of acid for different bottom product considerations. It can be seen from Table 4 that, in MeBZ and MeDC systems, all values of reflux ratio, and operation time, and the conversion level of acid increase gradually with increasing product concentration specifications. For MeSC system, the batch time and reflux ratio decrease gradually with improved product composition of MeSC. This is because that the distillation column has tried to remove methanol and water quicker and in a large quantity to fulfil the desired product requirements.

Table 4: Summary of optimization results for the three reaction systems for BRD column with equimolar ratio

\begin{tabular}{|c|c|c|c|}
\hline $\begin{array}{l}\text { Product Purity } \\
(\mathrm{kmol} \%)\end{array}$ & $\begin{array}{l}\text { Optimal Reflux } \\
\text { Ratio, } \mathrm{R}_{\mathrm{BRD}}(---)\end{array}$ & $\begin{array}{l}\text { Final Batch } \\
\text { time, } t_{F},(h)\end{array}$ & $\begin{array}{c}\text { Conversion of } \\
\text { Acid (\%) }\end{array}$ \\
\hline \multicolumn{4}{|c|}{ Methyl Decanoate (MeDC) System } \\
\hline 0.545 & 0.774 & 4.06 & 58.53 \\
\hline 0.555 & 0.824 & 5.22 & 59.52 \\
\hline 0.560 & 0.850 & 6.12 & 60.00 \\
\hline 0.570 & $--^{a}$ & $--^{a}$ & $--^{\mathrm{a}}$ \\
\hline \multicolumn{4}{|c|}{ Methyl Salicylate (MeSC) System } \\
\hline 0.765 & 0.545 & 2.02 & 80.83 \\
\hline 0.775 & 0.453 & 1.68 & 81.93 \\
\hline 0.780 & 0.383 & 1.49 & 82.54 \\
\hline 0.785 & $--^{a}$ & $--^{a}$ & $--^{a}$ \\
\hline \multicolumn{4}{|c|}{ Methyl Benzoate (MeBZ) System } \\
\hline 0.725 & 0.835 & 5.57 & 76.58 \\
\hline 0.735 & 0.839 & 5.73 & 77.58 \\
\hline
\end{tabular}




\begin{tabular}{rccc}
0.745 & 0.844 & 5.90 & 78.58 \\
0.755 & $--^{\mathrm{a}}$ & $-{ }^{\mathrm{a}}$ & --- $^{\mathrm{a}}$ \\
\hline${ }^{\mathrm{a}}$ Infeasible. & &
\end{tabular}

To remove water (byproduct), reflux ratio has to be decreased and thus enhancing the chemical reaction further to the right by converting more and more salicylic acid (Table 4). As before, it was difficult to obtain a higher purity of methyl esters using BRD operation for both reaction schemes.

\subsubsection{The performance of sr-BRD column with excess methanol}

The split-reflux batch reaction distillation column (sr-BRD) with side reflux to the reboiler (Figure 1b) is novel and is proposed/examined in this work for all the reaction systems and the performance of sr-BRD column is compared with those of the BRD column as highlighted earlier for excess methanol case. Note, the operating conditions and sr-BRD specifications are the same as those in the BRD process for this purpose. Note the pot drum amount is kept at $2.5 \mathrm{kmol}$ for all cases. The minimum batch time, optimum reflux ratio for both reflux rate, the conversion of acid together with total quantity of refluxed liquid for srBRD process for various product concentrations are summarized in Table 5. There it is observed Table 5 that the total batch time, reflux ratio and the total refluxed amount (split reflux) gradually increases with increasing the product purity requirements. Note increasing total batch time clearly helped rising the conversion rate of acid. Note, for MeDC scheme, sharp increase in both processing time and quantity of refluxed rate is noticed in line with the increase in MeDC purity from 0.715 to 0.720 (mole fraction). This is due to the fact that the sr-BRD column operated at a higher reflux ratio to suppress the MeDC travelling up the column but demanded a higher batch time as compared to the others to meet the product constraint. A comparison of the results between the conversion ratio of acids (DeC, ScA, and BeZ) employing the sr-BRD operation and the BRD column (Table 3) shows that for a given 
amount of bottom product in the still pot $(2.5 \mathrm{kmol})$ the sr-BRD column can produce MeDC, MeSC, and MeBZ at much higher purities ( 0.720 as compared to 0.555 mole fraction for MeDC system), (0.810 as compared to 0.770 mole fraction for MeSC system), and (0.850 as compared to 0.740 mole fraction for MeBZ system), and can convert more decanoic acid by reaction with methanol ( $81.27 \%$ as opposed to only $62.95 \%)$, more salicylic acid into methyl salicylate ( $91.18 \%$ as opposed to only $86.30 \%$ ), and more benzoic acid into methyl benzoate (94.84\% as opposed to only $82.80 \%)$.

However, note for MeDC system, use of sr-BRD for product purity more than 0.72 molefraction will not be economically justified due to significantly higher batch time leading to significantly higher operating cost for very little improvement in product purity.

Table 5: Summary of optimization results for the three reaction systems for sr-BRD column with excess methanol

\begin{tabular}{|c|c|c|c|c|c|}
\hline $\begin{array}{l}\text { Product Purity } \\
\qquad(\mathrm{kmol} \%)\end{array}$ & $\begin{array}{c}\text { Optimal } \\
\text { Reflux Rate, } \\
(\mathrm{kmol} / \mathrm{h})\end{array}$ & $\begin{array}{c}\text { Optimal } \\
\text { Reflux } \\
\text { Ratio, } \mathrm{R}_{\text {sr-BRD }}\end{array}$ & $\begin{array}{c}\text { Final Batch } \\
\text { time, } \\
\mathrm{t}_{\mathrm{F}},(\mathrm{h})\end{array}$ & $\begin{array}{l}\text { Conversion } \\
\text { of } \\
\text { Acid }(\%)\end{array}$ & $\begin{array}{c}\text { Total } \\
\text { Refluxed } \\
\text { Amount, }(\mathrm{kmol})\end{array}$ \\
\hline \multicolumn{6}{|c|}{ Methyl Decanoate (MeDC) System } \\
\hline 0.705 & 2.05 & 0.958 & 21.66 & 79.67 & 44.36 \\
\hline 0.715 & 2.10 & 0.975 & 36.52 & 80.77 & 76.60 \\
\hline 0.720 & 1.99 & 0.988 & 74.84 & 81.27 & 148.90 \\
\hline \multicolumn{6}{|c|}{ Methyl Salicylate (MeSC) System } \\
\hline 0.795 & 0.88 & 0.505 & 1.86 & 89.51 & 1.64 \\
\hline 0.805 & 1.31 & 0.700 & 3.06 & 90.50 & 4.00 \\
\hline 0.810 & 1.60 & 0.816 & 5.00 & 91.18 & 7.98 \\
\hline \multicolumn{6}{|c|}{ Methyl Benzoate (MeBZ) System } \\
\hline 0.830 & 0.15 & 0.907 & 9.92 & 92.46 & 1.53 \\
\hline 0.840 & 1.02 & 0.916 & 11.00 & 93.83 & 11.21 \\
\hline 0.850 & 0.69 & 0.920 & 11.47 & 94.84 & 7.91 \\
\hline
\end{tabular}


The sr-BRD operation is performed to return the accumulated methanol at the top plate of the batch column (lightest but reactant) to the unconverted component (acid) and thus have further reaction to occur which enhance the overall conversion. However, for the MeDC system, the sr-BRD column requires operating at high reflux ratio and with longer batch time to make sure water is sufficiently taken out from the bottom tank to satisfy the product purity.

For both MeSC and MeBZ schemes, operating at low reflux ratio and reflux rate ensures both removal of water and re-union of methanol at the reboiler drum to shift the chemical reaction forward. Shorter operating batch time was also feasible for increasing the conversion of acid as compared to MeDC system. In terms of reflux rates, the behaviour of MeDC system is a quite different from that in MeSC and MeBZ systems using sr-BRD column, higher reflux ratio with higher operating batch time, as well as higher rate of refluxed rate are needed for increasing product purity as compared to MeSC and MeBZ systems.

This is due to the difference in alcohol-acid boiling point temperature for MeDC system is much higher than that of the MeSC and MeBZ systems. Therefore, total quantity of refluxed methanol for MeDC scheme was much bigger than that of MeSC and MeBZ schemes. As can be observed also, the difference of boiling points between the acid- methyl ester for MeBZ scheme is much higher than those of the MeSC and MeDC schemes, respectively, and thus makes the separation of MeBZ is much easier than the separation of MeSC and MeDC.

Therefore, the maximum achievable conversion of acid and purity of methyl ester in MeBZ scheme is higher than that achieved for MeSC and MeDC schemes. Clearly, MeBZ system was found to provide better operational flexibility, highest conversion rate of limiting reactant, and maximum achievable purity of methyl ester as compared to MeSC and MeDC systems.

\subsubsection{The performance of sr-BRD column at equimolar feed ratio}


The operational flexibility and feasibility of sr-BRD mode as a potential option for the synthesis of a number of methyl esters is investigated. As mentioned before in section 4.3.3, the initial feed with excess methanol could increase the overall conversion of carboxylic acids, but with decreased bottom product composition. Here, the sr-BRD process is studied with equimolar feed ratio case, where the desired product amount is still at $2.5 \mathrm{kmol}$. The optimal reflux rate, reflux ratio, batch time, total refluxed amount over the batch time, and the conversion of acid are summarized in Table 6. Table 6 indicate that for all reaction systems, the side reflux rate, the reflux ratio, batch time, and the conversion increase as the product purity increases. The results show that sr-BRD can yield higher purity product $(0.740$ mole fraction of MeDC system, 0.825 mole fraction of MeSC system, and 0.875 mole fraction of MeBZ system) compared to those obtained by BRD mode of operation (Table 4). To accomplish this, the reflux ratio has to rise gradually to supress the large quantity of water in the refluxed side rate to push the reaction forward. However, although the purities of MeDC, MeSC, and MeBZ increase gradually at equimolar feed case in sr-BRD column as compared to those in sr-BRD with excess methanol (Table 5), the maximum conversions of acid obtained are $79.01 \%$ for MeDC system, $87.69 \%$ for MeSC system, and $92.22 \%$ for MeBZ system, which are much lower than those of sr-BRD with excess feed ratio as shown in Figure 2. As discussed before, MeBZ case is found to offer much better performance than MeDC, and MeSC cases in terms of higher conversion rate, and maximum achievable concentration of ester produced (Table 6, Figure 2).

However, note for MeDC system, use of sr-BRD for product purity more than 0.735 molefraction will not be economically justified due to significantly higher batch time leading to significantly higher operating cost for very little improvement in product purity.

Table 6: Summary of optimization results for the three reaction systems for sr-BRD column with equimolar ratio

\begin{tabular}{|c|c|}
\hline Product Purity & Optimal \\
\hline
\end{tabular}




\begin{tabular}{cccccc}
\hline $\begin{array}{c}\text { (kmol \%) } \\
\text { Reflux Rate, } \\
(\mathrm{kmol} / \mathrm{h})\end{array}$ & $\begin{array}{c}\text { Reflux } \\
\text { Ratio, } \mathrm{R}_{\text {sr-BRD }}\end{array}$ & $\begin{array}{c}\text { time, } \\
\mathrm{t}_{\mathrm{F}},(\mathrm{h})\end{array}$ & $\begin{array}{c}\text { of } \\
\text { Acid (\%) }\end{array}$ & $\begin{array}{c}\text { Refluxed } \\
\text { Amount, (kmol) }\end{array}$ \\
\hline 0.725 & 2.06 & 0.974 & 35.89 & 77.49 & 73.90 \\
0.735 & 2.07 & 0.987 & 73.35 & 78.50 & 151.98 \\
0.740 & 2.08 & 0.995 & 185.95 & 79.01 & 386.95 \\
0.805 & 0.74 & 0.512 & 1.88 & 86.04 & 1.40 \\
0.815 & 1.18 & 0.693 & 3.00 & 87.36 & 3.53 \\
0.825 & 1.41 & 0.895 & 8.73 & 87.69 & 12.29 \\
\hline 0.860 & & Methyl Decanoate (MeDC) System & \\
0.870 & 0.34 & 0.896 & 8.82 & 90.13 & 3.01 \\
0.875 & 1.31 & 0.907 & 9.91 & 91.73 & 12.94 \\
& 1.31 & 0.909 & 10.14 & 92.22 & 13.27 \\
\hline
\end{tabular}

Figure 3 shows the reflux rate and reflux ratio at the equimolar feed amount and different MeBZ product purities for all batch times for sr-BRD configuration. It can be seen from Table 6 also that higher product concentration of esters and higher conversion ratio of acids are accomplished. Some investigators disregarded the impacts of azeotrope formation and acid solubility for the production of isopropyl palmitate system due to the high conversion ratio of palmitic acid of $99.40 \%$ accomplished in their work (Chen et al., 2012, Zhang et al., 2015). Note that, although the $\mathrm{MeBZ}-\mathrm{H}_{2} \mathrm{O}$ form minimum-boiling azeotrope, their influences are ignored also in our work due to higher concentration of esters produced and higher conversion rate of carboxylic acids are attained by using the sr-BRD operation (see Tables 5 and 6). Figures 4 and 5 show the composition profiles of the accumulator tank and the reboiler for the MeDC case $\left(\mathrm{x}_{\mathrm{MeDC}}^{*}=0.560\right.$ mole fraction for $\mathrm{BRD}$, and 0.740 mole fraction for sr-BRD), while Figures 6 and 7 show the same for the MeSC case $\left(x_{\text {MeSC }}^{*}=0.780\right.$ mole fraction for BRD, and 0.825 mole fraction for sr-BRD), and Figures 8 and 9 show the same 
for the MeBZ case $\left(\mathrm{x}_{\mathrm{MeBZ}}^{*}=0.745\right.$ mole fraction for $\mathrm{BRD}$, and 0.875 mole fraction for srBRD), respectively at the equimolar feed case for both BRD and sr-BRD columns. Note that for sr-BRD mode (MeDC case), the batch time increases sharply affecting the total amount of refluxed rate (Table 6, Figure 5) helping to enhance the product concentration from 0.735 to 0.740 (mole fraction). For product concentration of 0.740 mole fraction, the sr-BRD system operated at the highest reflux ratio and longest batch time allowing high purity methanol to be refluxed back to the column by both reflux rates. For all reaction schemes, the mole fraction of water ( $2^{\text {nd }}$ boiling component) rises from zero and gets to the maximum value and then decreases gradually. This is due to its separation in the top tank (Figures 4, 6, and 8). In the reboiler tank, as the reaction continues, at the beginning the reactant concentrations (decanoic acid and methanol) for MeDC system, (salicylic acid and methanol) for MeSC system, and (benzoic acid and methanol) for MeBZ system declines rapidly, whereas, the mole fractions of methyl decanoate, methyl salicylate, and methyl benzoate rise (Figures 5, 7, and 9). Note also, methyl salicylate product reached the desired purity at the shorter batch time for MeSC case than methyl benzoate for MeBZ case, and methyl decanoate for MeDC case (Figures 7, and 9). Note, the performance of sr-BRD process is compared with the performance of classical BRD column in terms of maximum achievable purity and highest reaction conversion. However, the new sr-BRD column was suggested to increase the product purity and the reaction conversion and thus in some cases required high operating time and operating cost in order to achieve the desired product considerations. However, a comparison of the results of sr-BRD operation with the continuous reactive distillation column using the energy saving as the performance measure is beyond the scope of the present study. Note, the amount of bottom product is kept constant at $2.5 \mathrm{kmol}$ for both BRD/sr-BRD columns for all presented cases. As mentioned before, the novel sr-BRD scheme was proposed to improve the process efficiency and the profitability and decrease the operating cost by increased the 
product purity and the conversion of limiting reactant. The still pot temperature profiles of the sr-BRD system for the MeDC case $\left(x_{\mathrm{MeDC}}^{*}=0.740\right.$ mole fraction $)$, for the MeSC case $\left(x_{\text {MeSC }}^{*}=0.825\right)$, and for the MeBZ case $\left(x_{\text {MeBZ }}^{*}=0.875\right)$ at the equimolar feed amount are given in Figures 10, 11, and 12, respectively. For both MeDC and MeSC systems, the reboiler temperature rises gradually with time in both cases at the initial period due to the presence of a significant amount of water. After a certain period as the light component (methanol) is removed from the bottom tank, the heaviest component (acid) is remined in the still pot, therefore the reaction temperature starts to rise. While in MeBZ system higher operating temperature is observed due to more benzoic acid in the feed mixture. It can be noted from Figure 12 that the operation temperature of the still pot is increased and reached the maximum value $(575 \mathrm{~K})$ at $5.5 \mathrm{~h}$ and then drops down to $363 \mathrm{~K}$ at the end of the operation time. This is due to having more methanol reacting with benzoic acid in the bottom tank (reducing methanol in the receiver tank) and yielding more ester by the reaction (and thus increasing the reaction conversion as presented in Table 6). 


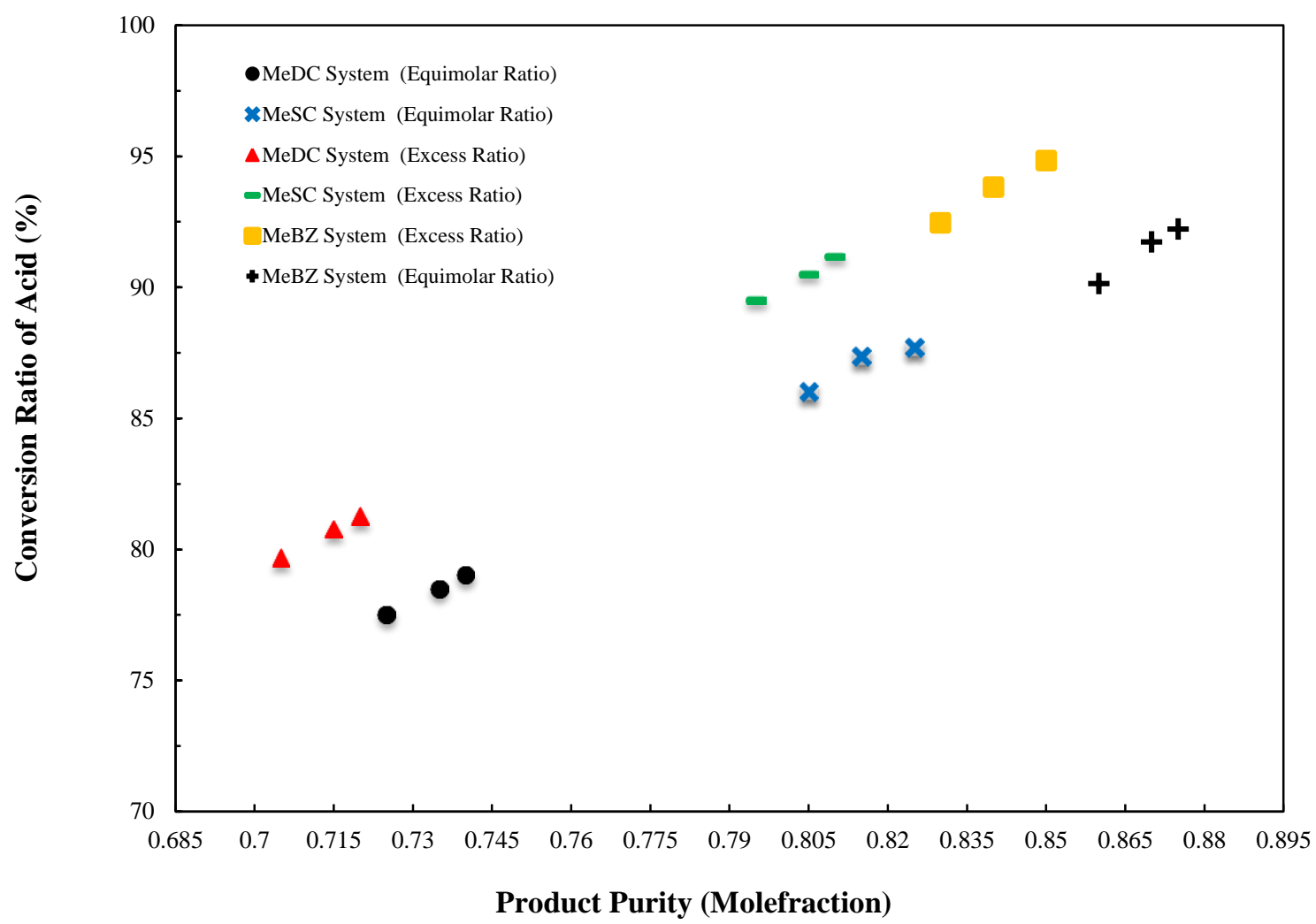

Figure 2: The conversion of acid for three reaction systems for the sr-BRD operation at both equimolar and excess methanol ratios.

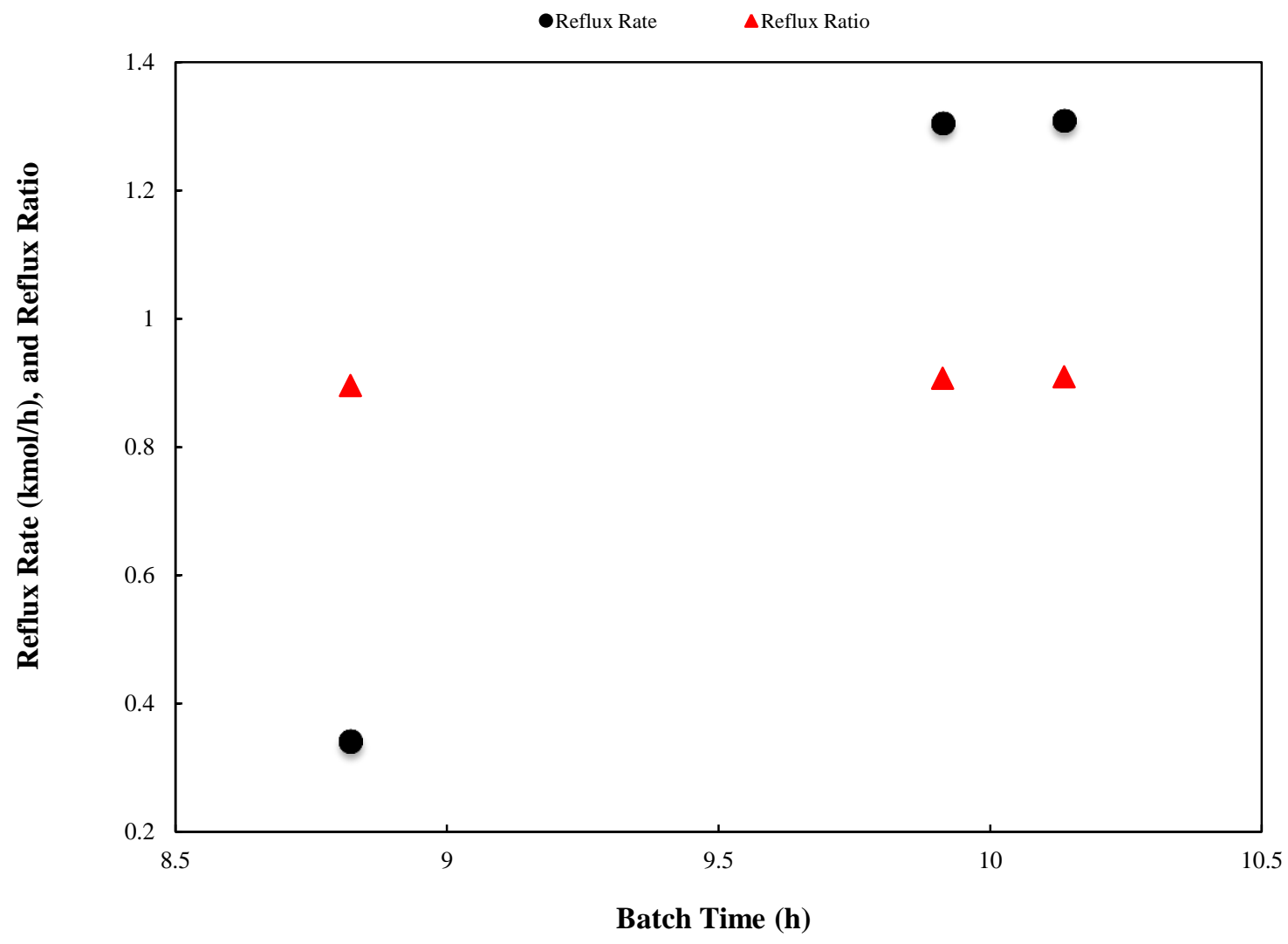

Figure 3: The reflux rate and reflux ratio for MeBZ system for the sr-BRD operation. 


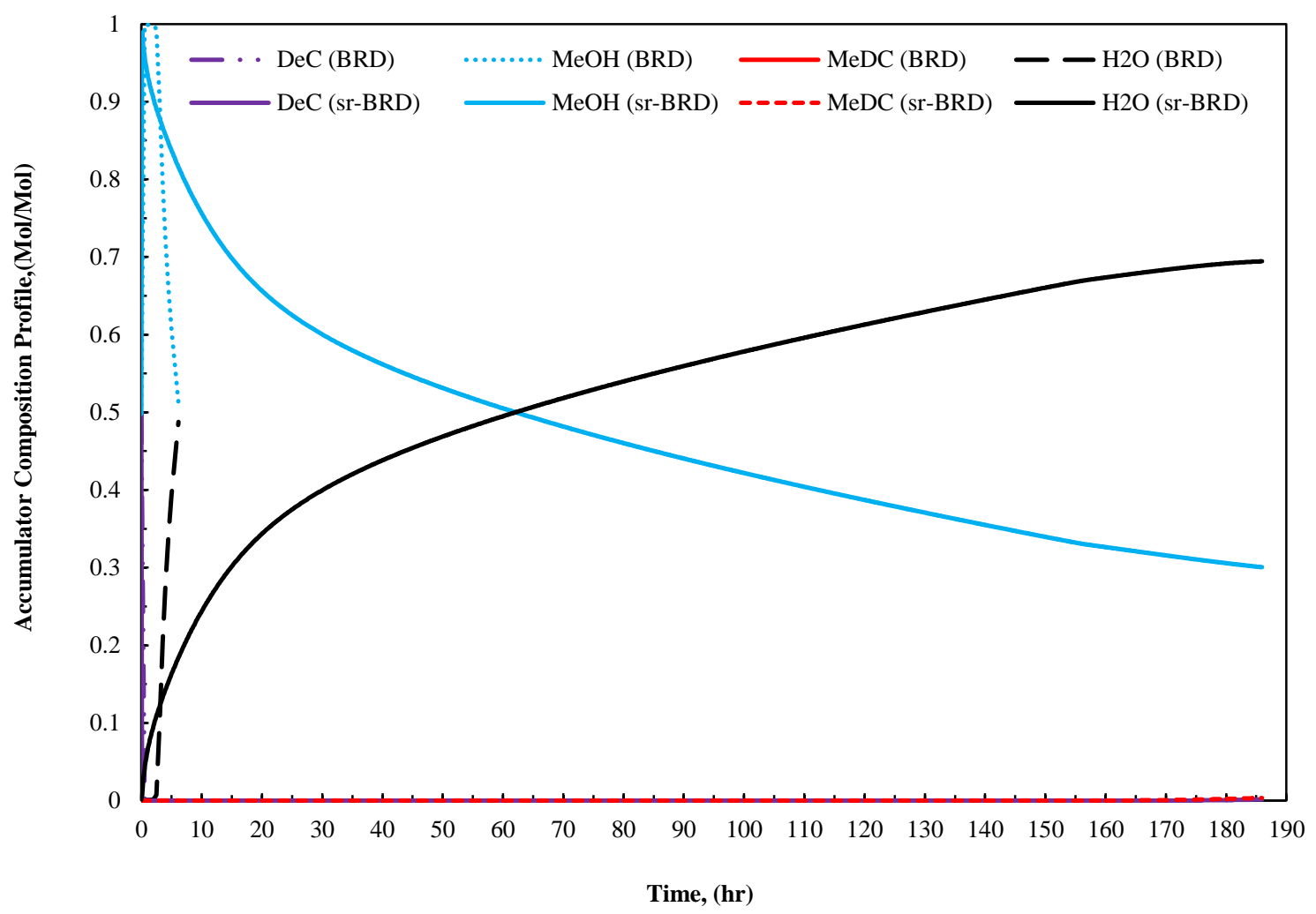

Figure 4: The accumulator composition of BRD and sr-BRD for MeDC system at the equimolar feed ratio.

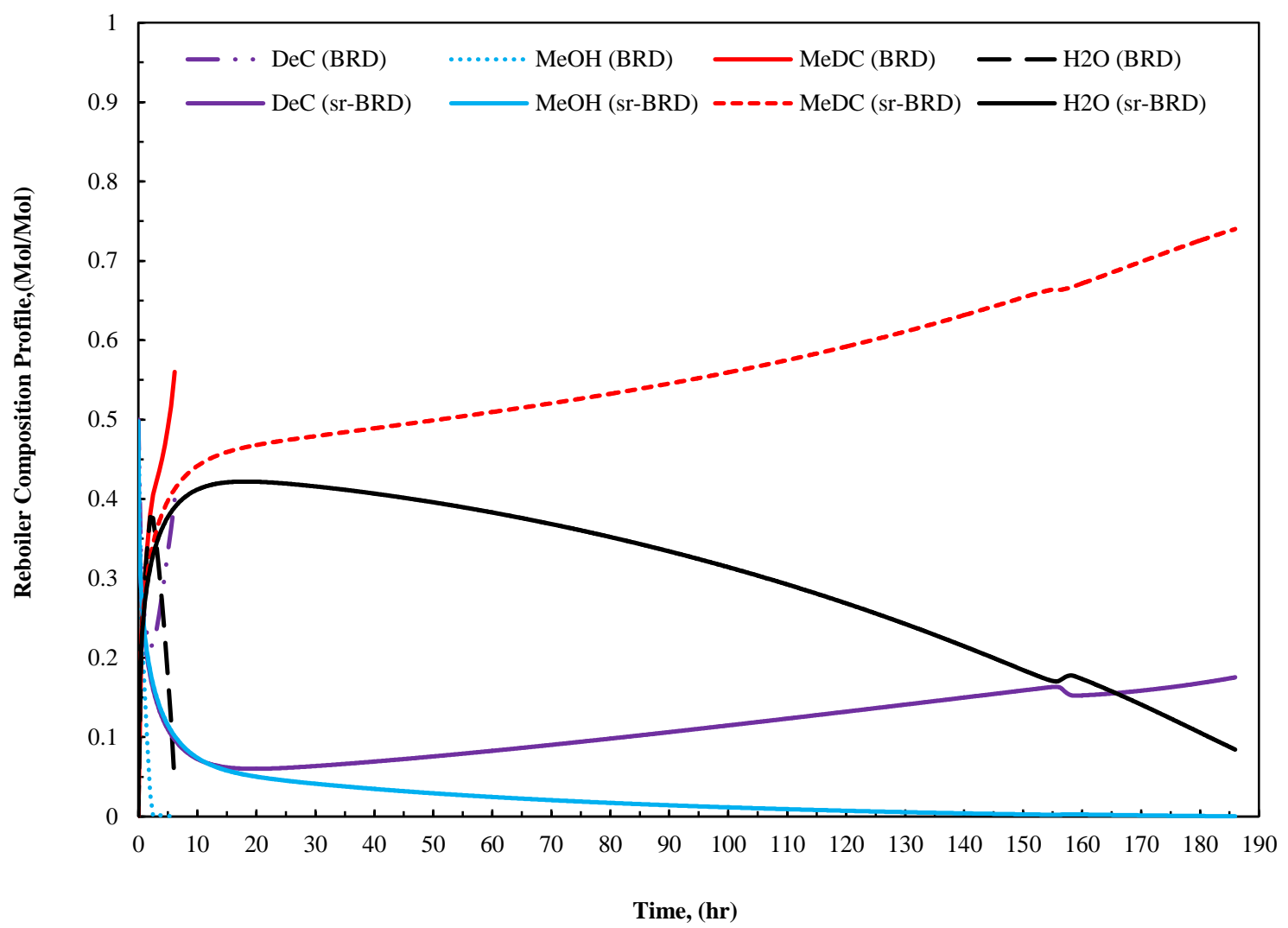

Figure 5: The reboiler composition of BRD and sr-BRD for MeDC system at the equimolar feed ratio. 


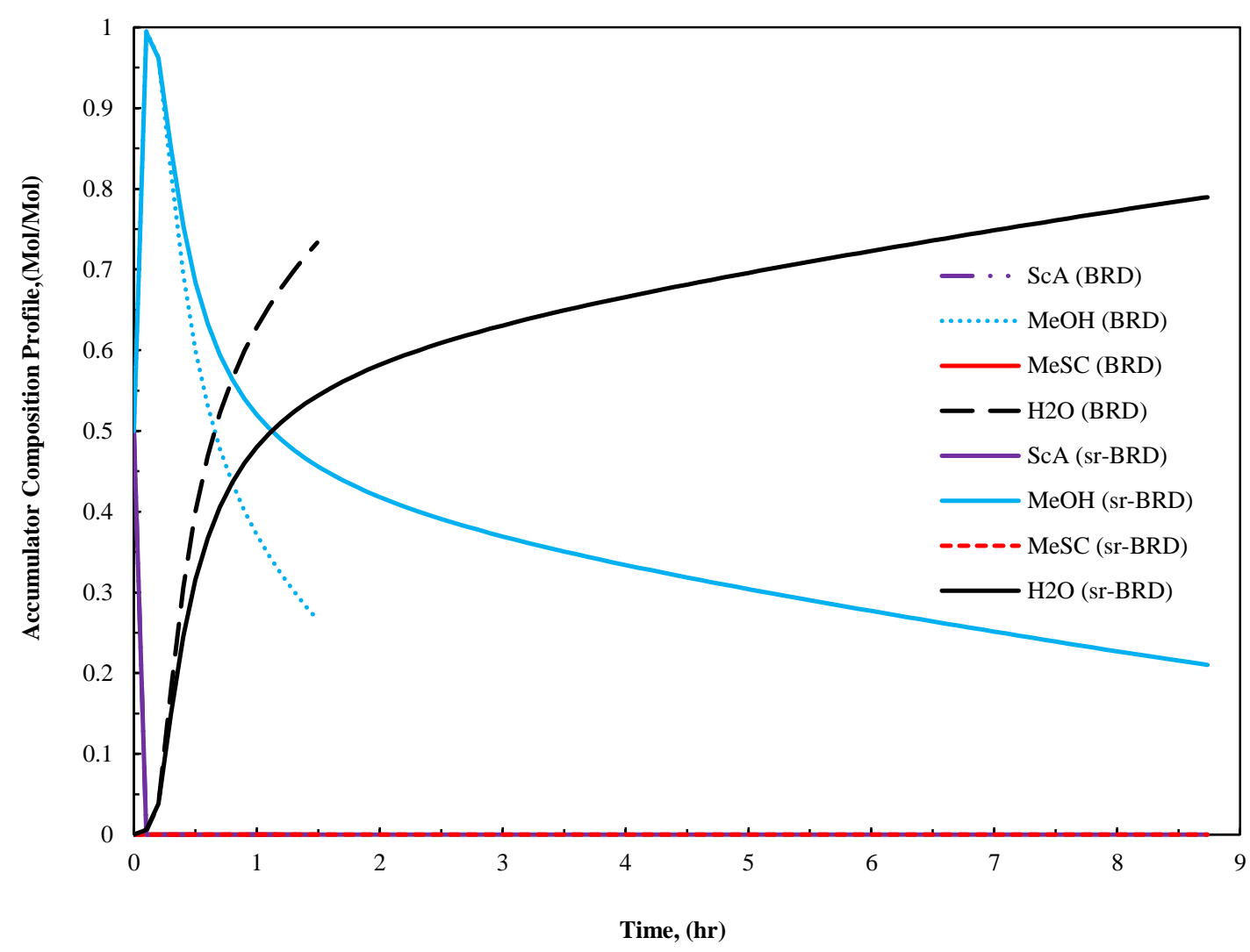

Figure 6: The accumulator composition of BRD and sr-BRD for MeSC system at the equimolar feed ratio.

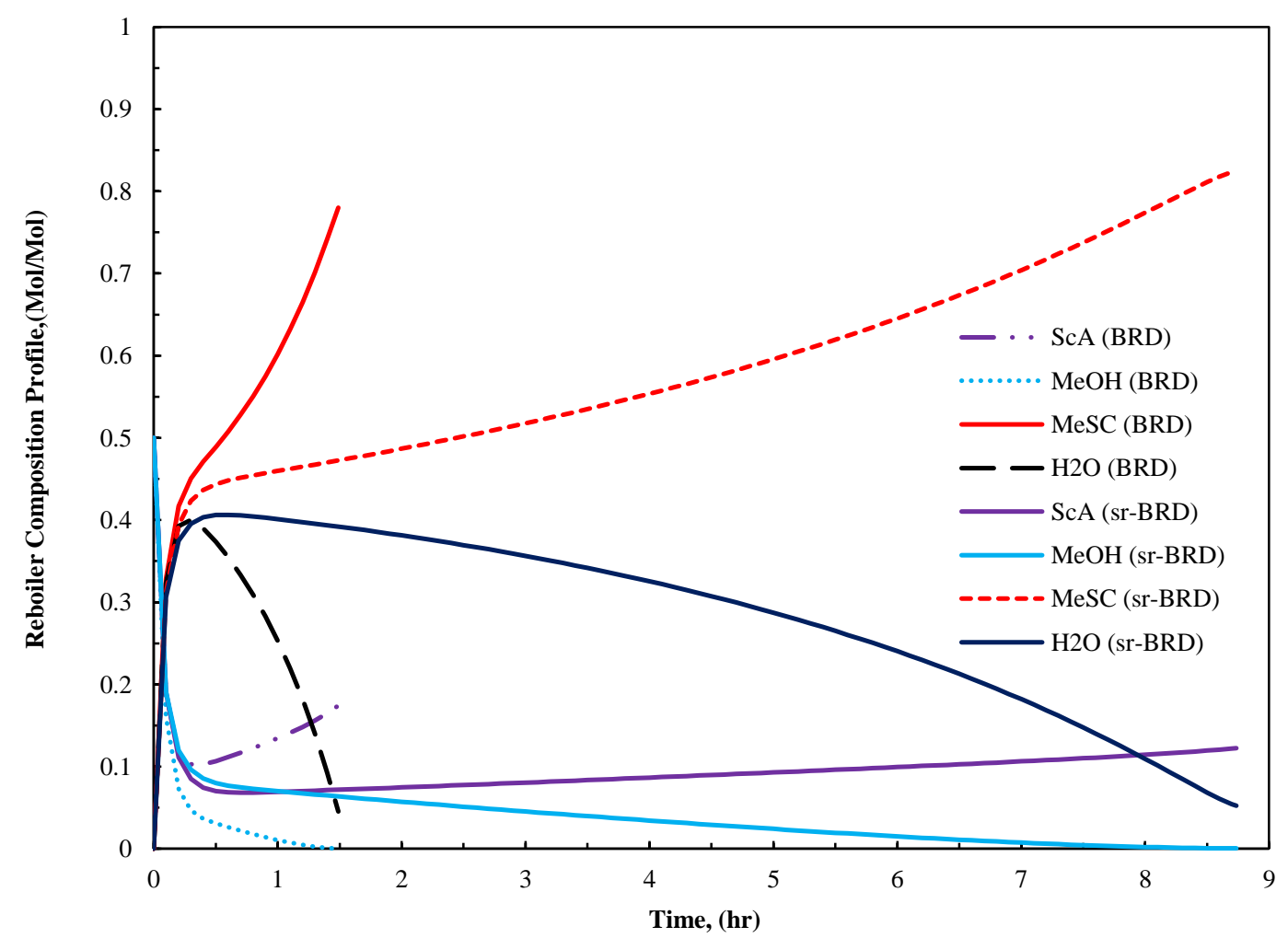

Figure 7: The accumulator composition of BRD and sr-BRD for MeSC system at the equimolar feed ratio. 


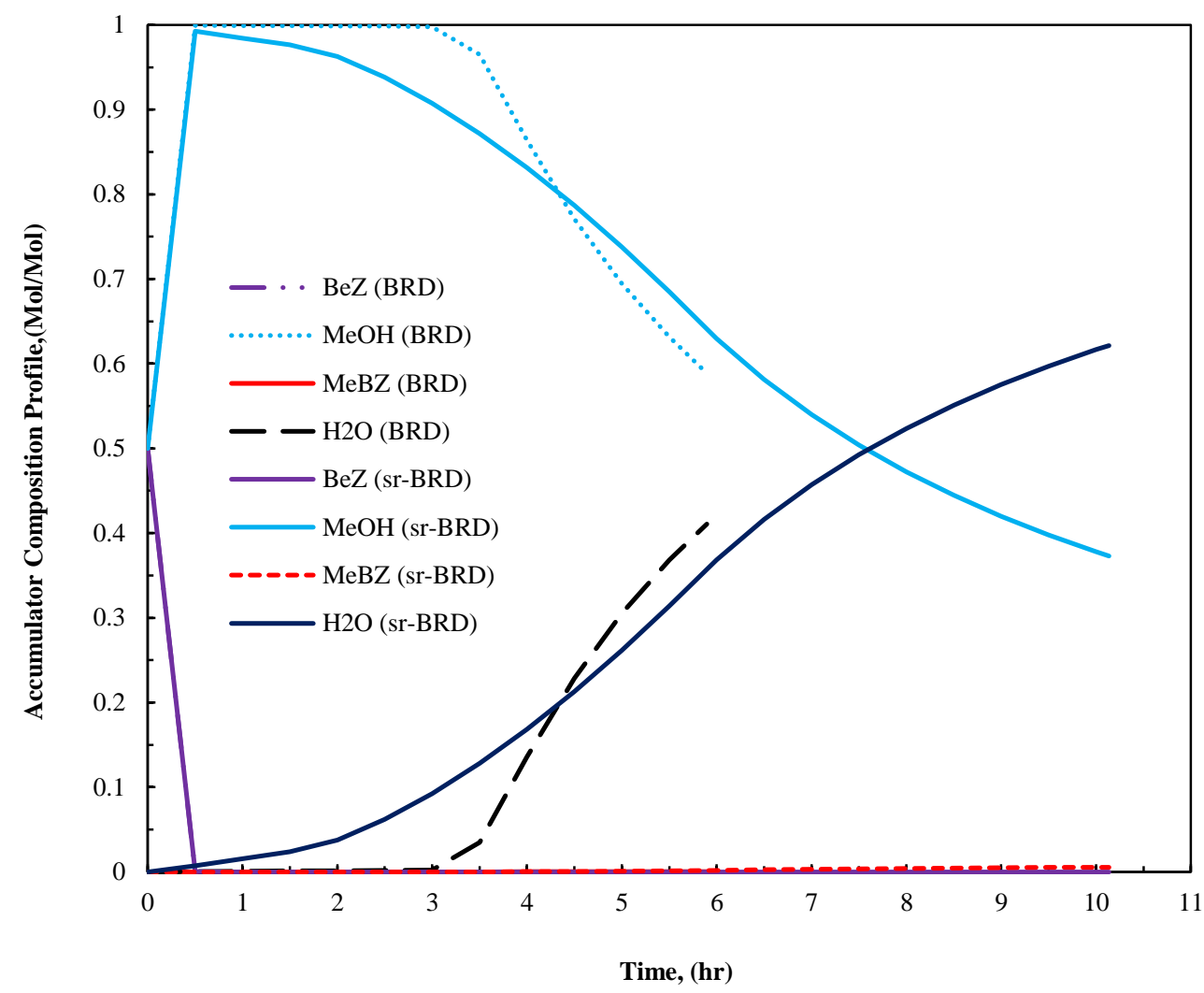

Figure 8: The accumulator composition of BRD and sr-BRD for MeBZ system at the equimolar feed ratio.

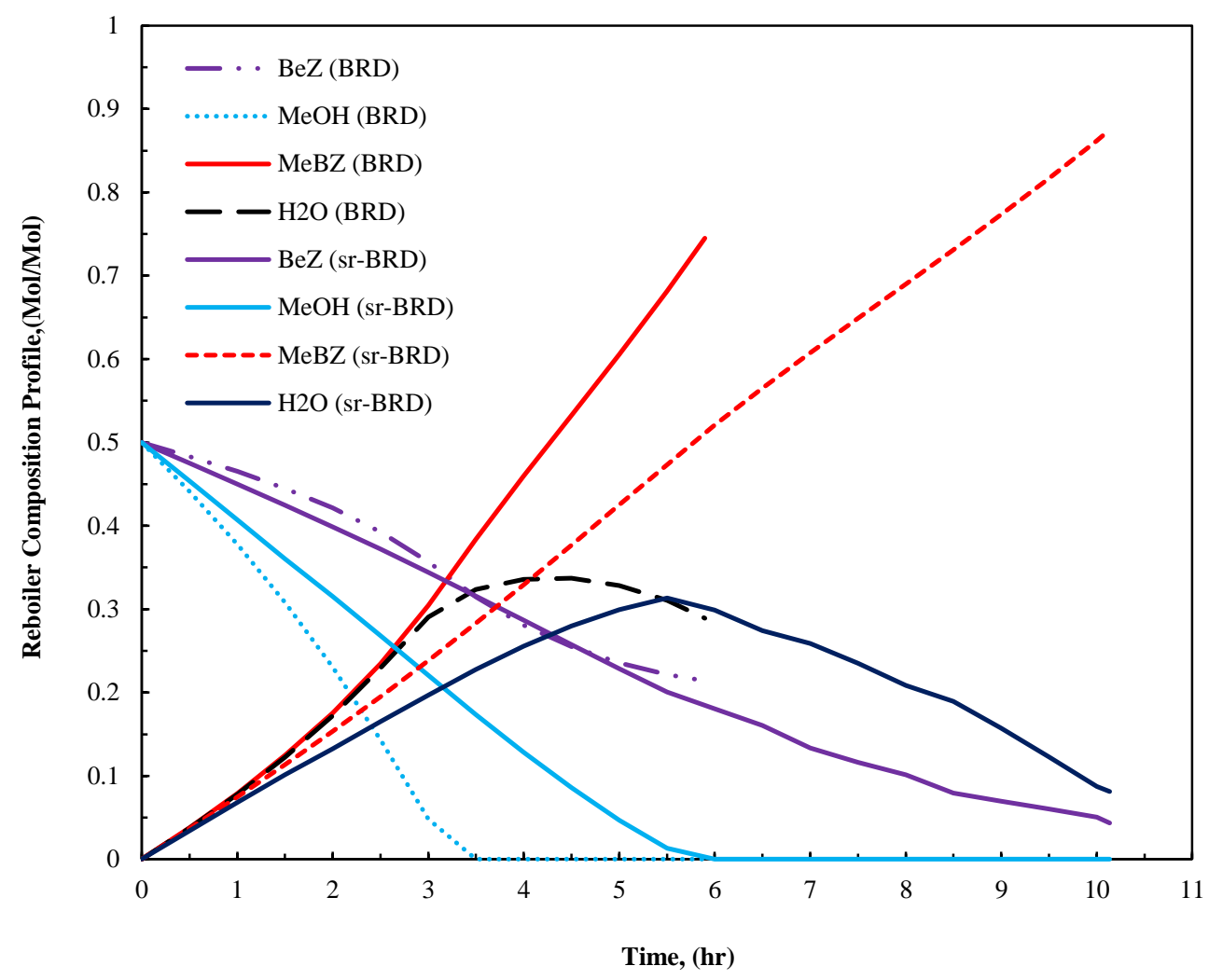

Figure 9: The reboiler composition of BRD and sr-BRD for MeBZ system at the equimolar feed ratio. 


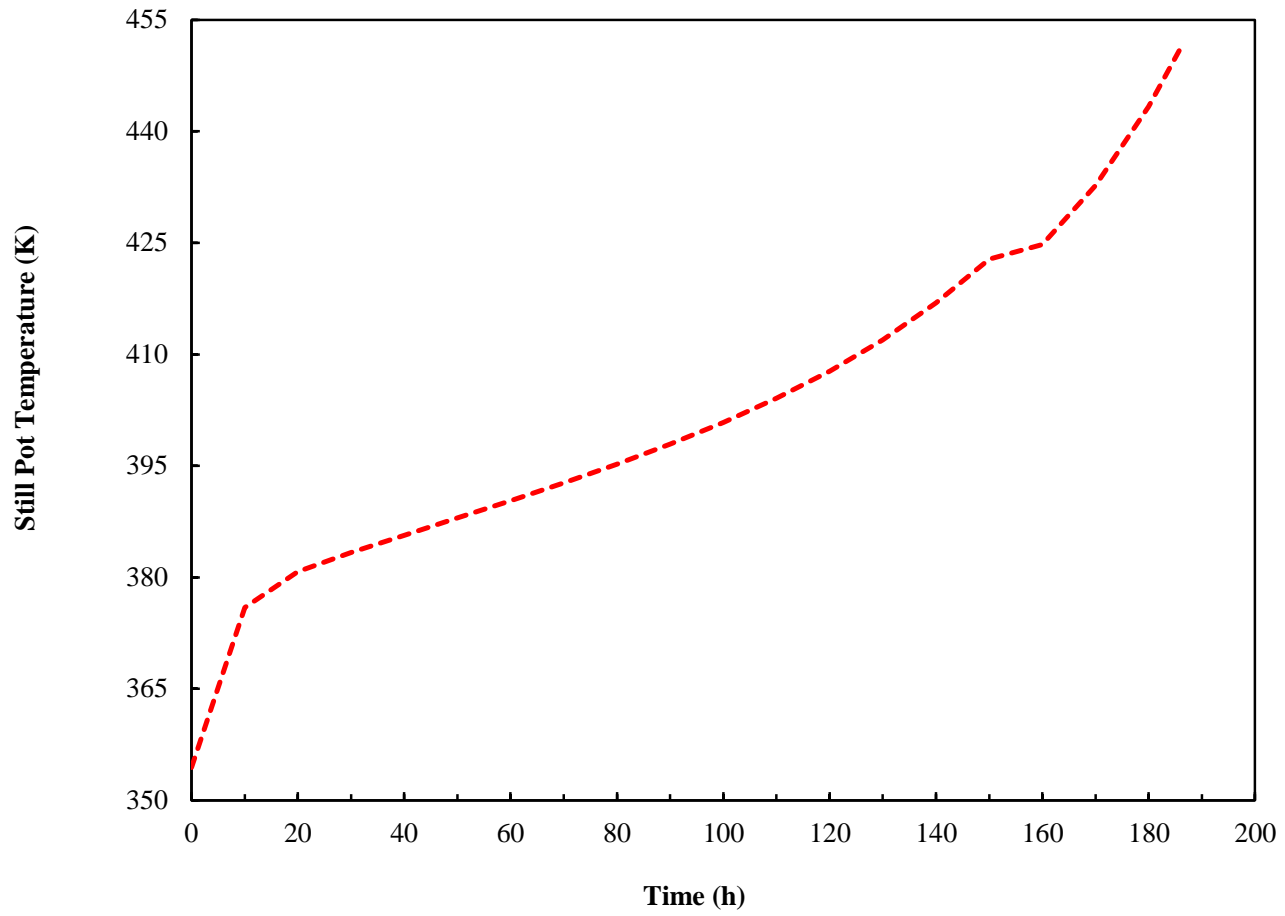

Figure 10: The still pot temperature for MeDC system for the sr-BRD operation.

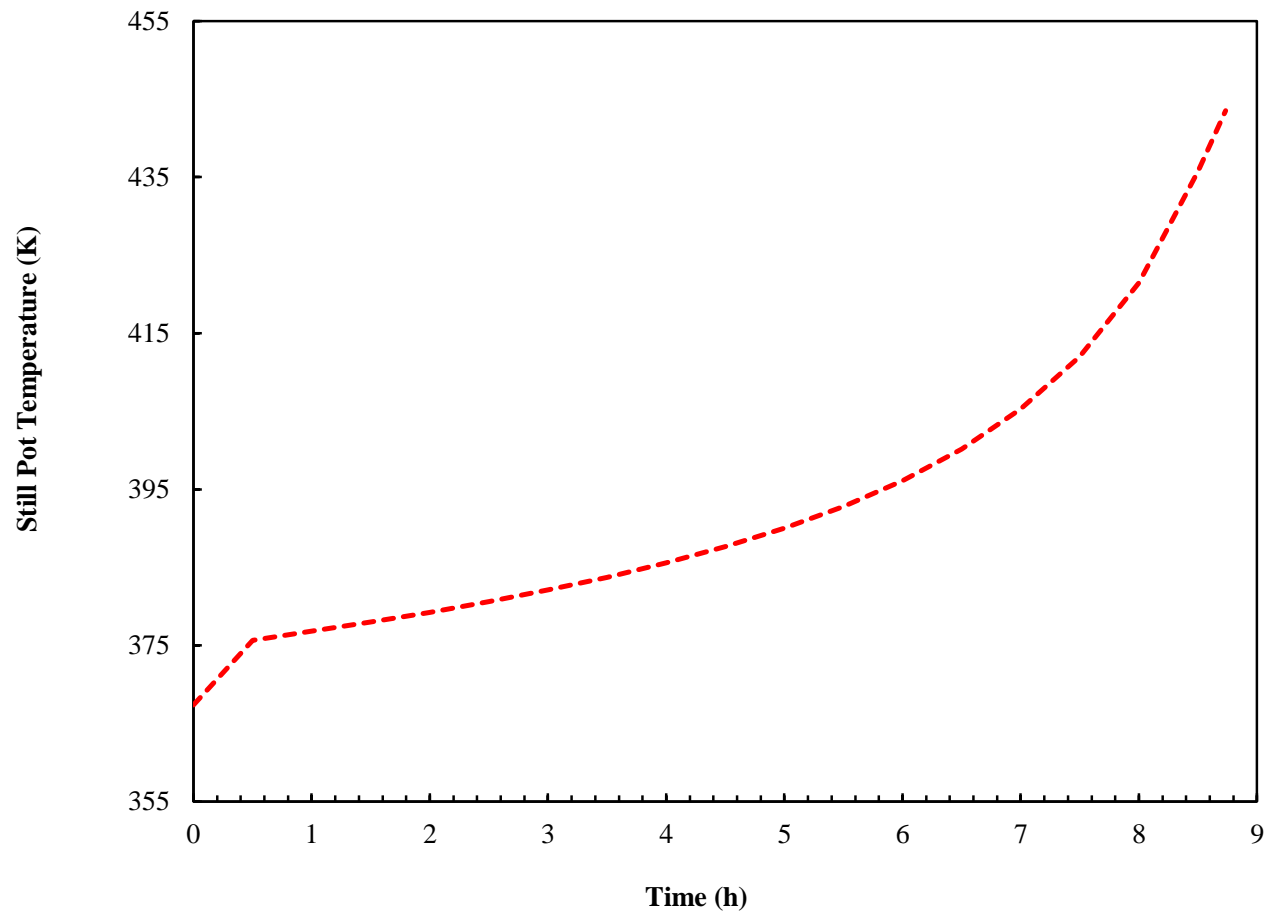

Figure 11: The still pot temperature for MeSC system for the sr-BRD operation. 


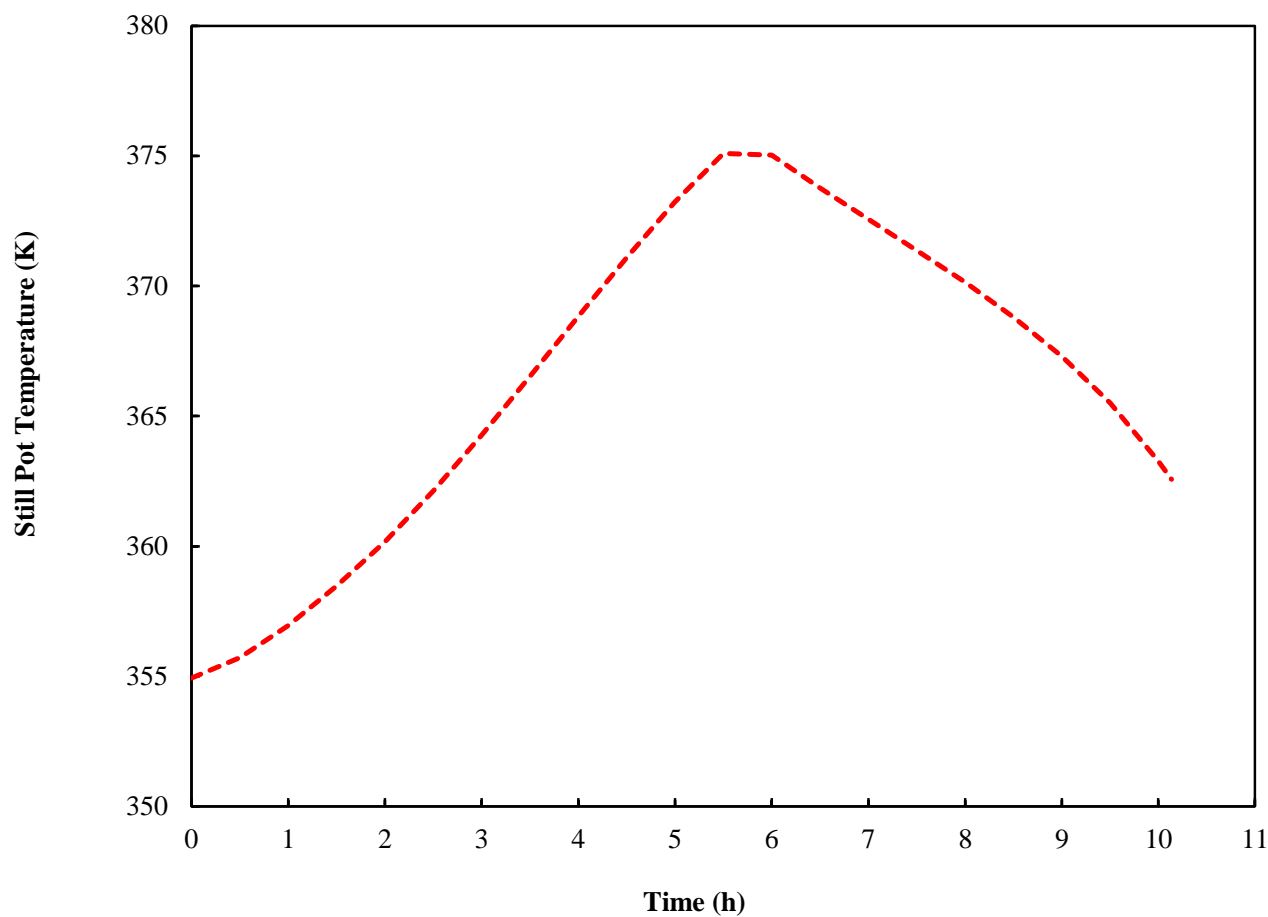

Figure 12: The still pot temperature for MeBZ system for the sr-BRD operation.

\section{Conclusions}

Here, the formation of MeDC, MeSC, and MeBZ via the esterification reactions of acids with methanol is considered. The efficiency of applying the traditional conventional batch reactive column is very limited because of the separation of methanol from the acid in the reaction zone due to wide variances in boiling point temperatures between the reaction components. Hence, as the operation continues, the reverse chemical reaction is being activated because of the depletion of methanol (one of the forward reaction reactants in those esterification reactions), resulting a significant decrease in the conversion rate of limiting reactant employing either batch reactive or continuous reactive process.

To address this challenging problem and to enhance the conversion level of acid, a new splitreflux conventional batch reactive system (sr-BRD) configuration is proposed and examined herein. The optimal operations of those batch modes are evaluated in terms of batch time, conversion of acid and product purity for a given separation task. Detailed dynamic models 
for these columns are constructed using gPROMS software and are embedded within the dynamic optimization problem. The optimization constants such as reflux ratio for BRD process, and the side reflux rate strategy for sr-BRD column on the production batch time are considered. Obviously, the performance of the split-reflux batch distillation operation (sr$\mathrm{BRD}$ ) is found to be superior compared to the conventional batch distillation column (BRD) in terms of attaining higher conversion and thus product concentration. Note also, the performance of sr-BRD operation with the equimolar ratio case was preferable to the sr-BRD operation with excess feed ratio in terms of maximum product purity for both esterification reactions.

Also, it was found that the use of additional methanol in the feed mixture was necessary in split-reflux batch reactive distillation operation to only improve the conversion rate of the acid in both MeDC and MeSC systems. Finally Note, MeBZ Case was found to outperform the MeDC and MeSC systems in terms of highest achievable concentration of methyl esters and maximum reaction conversion.

\section{Nomenclature}

$\mathrm{B}_{\operatorname{Pr}}$

Activity of component i

$\mathrm{C}_{\mathrm{i}}$

The product amount in the reboiler drum

$\mathrm{kmol}$

BRD

Concentration of component $\mathrm{i}$

$\mathrm{Mol} / \mathrm{lit}$

CVP

Convectional batch distillation

DAEs

Control vector parameterisation

$\mathrm{H}^{\mathrm{L}}, \mathrm{h}^{\mathrm{V}}$

Differential algebraic equations

$\mathrm{H}_{\mathrm{a}}, \mathrm{H}_{\mathrm{C}}$

Liquid, and vapour enthalpy

$\mathrm{kJ} / \mathrm{kmol}$

$\mathrm{H}, \mathrm{H}_{\mathrm{N}}$

Accumulator and condenser holdups

$\mathrm{kmol}$

K

Trays and reboiler holdups, respectively

kmol

L

Vapour-liquid equilibrium

$\mathrm{L}_{\mathrm{D}}$

Liquid flow rate

$\mathrm{kmol} / \mathrm{h}$

Distillate rate

$\mathrm{kmol} / \mathrm{h}$ 


$\begin{array}{lll}\mathrm{L}_{\mathrm{S}} & \text { Reflux side 2 rate } & \mathrm{kmol} / \mathrm{h} \\ \mathrm{m}_{\mathrm{cat}} & \text { The catalyst weight } & \mathrm{kg} \\ \mathrm{NLP} & \text { Nonlinear programming problem } & - \\ \mathrm{OP} & \text { Optimisation problem } & - \\ \mathrm{Q}_{\mathrm{C}}, \mathrm{Q}_{\mathrm{R}} & \text { Condenser duty and reboiler heat duty } & \mathrm{kJ} / \mathrm{h} \\ \mathrm{R}_{\mathrm{BRD}} & \text { Reflux ratio for BRD } & - \\ \mathrm{R}_{\mathrm{sr}-\mathrm{BRD}} & \text { Reflux ratio for sr-BRD } & - \\ \mathrm{r}_{\mathrm{i}} & \text { Reaction rate } & - \\ \mathrm{SQP} & \text { Successive quadratic programming algorithm } & - \\ \mathrm{sr}-\mathrm{BRD} & \text { Split-reflux batch reactive distillation } & - \\ \mathrm{t}_{\mathrm{F}} & \text { Processing time } & \mathrm{h} \\ \mathrm{V}_{\mathrm{C}} & \text { Vapour Boil up rate } & \mathrm{kmol} / \mathrm{h} \\ \mathrm{x} & \text { Liquid concentration } & \text { molefraction } \\ \mathrm{x}_{\mathrm{a}} & \text { Accumulated distillate concentration } & \text { molefraction } \\ \mathrm{x}_{\mathrm{D}} & \text { Instant distillate concentration } & \text { molefraction } \\ \mathrm{y} & \text { Vapor concentration } & \text { molefraction }\end{array}$

\section{Greek Letters}

Superscripts and subscripts

i Component number

j Number of Plates

$\Delta \mathrm{n} \quad$ Change in moles due to chemical reaction

Abbreviations

$\begin{array}{ll}\mathrm{BeZ} & \text { Benzoic Acid } \\ \mathrm{DeC} & \text { Decanoic Acid } \\ \mathrm{H}_{2} \mathrm{O} & \text { Water } \\ \mathrm{MeBZ} & \text { Methyl Benzoate } \\ \mathrm{MeDC} & \text { Methyl Decanoate } \\ \mathrm{MeSC} & \text { Methyl Salicylate } \\ \mathrm{MeOH} & \text { Methanol } \\ \mathrm{ScA} & \text { Salicylic Acid }\end{array}$

\section{References}


Aqar, D. Y., Rahmanian, N. \& Mujtaba, I.M. (2016 a). Methyl Lactate Synthesis using Batch Reactive Distillation: Operational Challenges and Strategy for Enhanced Performance. Separation and Purification Technology,158,193-203.

Aqar, D.Y., Rahmanian, N. and Mujtaba, I.M. (2016 b). Integrated batch reactive distillation column configurations for optimal synthesis of methyl lactate. Chemical Engineering and Processing: Process Intensification, 108, pp.197-211.

Aqar, D.Y., Rahmanian, N. and Mujtaba, I.M. (2016 c). Optimal design and operation of semi-batch reactive distillation for methyl lactate synthesis with fixed product demand. In Computer Aided Chemical Engineering (Vol. 38, pp. 895-900). Elsevier.

Aqar, D.Y., Rahmanian, N. and Mujtaba, I.M. (2017a). Synthesis of methyl decanoate using different types of batch reactive distillation systems. Industrial \& Engineering Chemistry Research, 56(14), pp.3969-3982.

Aqar, D.Y., Rahmanian, N. and Mujtaba, I.M. (2017b). Feasibility of integrated batch reactive distillation columns for the optimal synthesis of ethyl benzoate. Chemical Engineering and Processing: Process Intensification, 122, pp.10-20.

Aqar, D.Y., Rahmanian, N. and Mujtaba, I.M. (2017c). Significant Profitability Improvement for Methyl Decanoate Production using Different Types of Batch Distillation. Chemical Engineering Transcation, 57.

Aqar, D.Y., Rahmanian, N. and Mujtaba, I.M. (2018a). Feasibility of Novel Integrated Dividing-Wall Batch Reactive Distillation Processes for the Synthesis of Methyl Decanoate. Separation and Purification Technology, 202, pp. 200-215.

Aqar, D.Y., Rahmanian, N. and Mujtaba, I.M. (2018b). Investigation about Profitability Improvement for Synthesis of Benzyl Acetate in Different Types of Batch Distillation Columns. Chemical Engineering Transactions, 70, pp.541-546.

Bochner, M.B., Gerber, S.M., Vieth, W.R. and Rodger, A.J. (1965). Ion exchange resincatalyzed esterification of salicylic acid with methanol. Industrial \& Engineering Chemistry Fundamentals, 4(3), pp.314-317.

Chandavasu, C. (1997). Pervaporation-assisted esterification of salicylic acid (Doctoral dissertation, New Jersey Institute of Technology, Department of Chemical Engineering, Chemistry, and Environmental Science).

Chen, H., Huang, K., Zhang, L. and Wang, S. (2012). Reactive distillation columns with a top-bottom external recycle. Industrial \& Engineering Chemistry Research, 51(44), pp.14473-14488.

DeGarmo, J.L., Parulekar, V.N. and Pinjala, V., (1992). Consider reactive distillation. Chemical Engineering Progress, 88(3), pp.43-50.

D'Souza, J. and Nagaraju, N., 2007. Esterification of salicylic acid with methanol/dimethyl carbonate over anion-modified metal oxides. Indian Journal of Chemical Engineering, (14), p.292-300.

Edreder, E.A., Mujtaba, I.M. and Emtir, M. (2011). Optimal operation of different types of batch reactive distillation columns used for hydrolysis of methyl lactate to lactic acid. Chemical engineering journal, 172(1), pp.467-475.

gPROMS, (2017). gPROMS Advanced User Guide. Process Systems Enterprise Ltd., London.

Jarullah, A.T., Mujtaba, I.M. and Wood, A.S. (2011). Whole crude oil hydrotreating from small-scale laboratory pilot plant to large-scale trickle-bed reactor: analysis of operational issues through modeling. Energy \& Fuels, 26(1), pp.629-641.

Kao, Y.L. and Ward, J.D. (2014a). Design and optimization of batch reactive distillation processes with off-cut. Journal of the Taiwan Institute of Chemical Engineers, 45(2), pp.411-420. 
Kao, Y.L. and Ward, J.D. (2014b). Improving Batch Reactive Distillation Processes with Off-Cut. Industrial \& Engineering Chemistry Research, 53(20), pp.8528-8542.

Kao, Y.L. and Ward, J.D. (2015a). Batch reactive distillation with off-cut recycling. Industrial \& Engineering Chemistry Research, 54(7), pp.2188-2200.

Kao, Y.L. and Ward, J.D. (2015b). Simultaneous Optimization of the Design and Operation of Batch Reactive Distillation Processes. Industrial \& Engineering Chemistry Research, 55(1), pp.267-278.

Lamba, R., Kumar, S. and Sarkar, S. (2018). Esterification of decanoic acid with methanol using Amberlyst 15: Reaction kinetics. Chemical Engineering Communications, pp.114.

Machado, G.D., Aranda, D.A., Castier, M., Cabral, V.F. and Cardozo-Filho, L. (2011). Computer simulation of fatty acid esterification in reactive distillation columns. Industrial \& Engineering Chemistry Research, 50(17), pp.10176-10184.

Mujtaba, I.M. (2004). Batch distillation: Design and operation. London: Imperial College Press.

Nad, M. and Spigel, L. (1987). Simulation of batch distillation by computer and comparison with experiment, In Proceedings of CEF 87. Sicily, Italy, 737.

Ullmann's Encyclopedia of Industrial Chemistry (2014). Ullmann's Fine Chemicals, Wiley.

Shi, H., Zhu, W., Li, H., Liu, H., Zhang, M., Yan, Y. and Wang, Z. (2010). Microwaveaccelerated esterification of salicylic acid using Brönsted acidic ionic liquids as catalysts. Catalysis Communications, 11(7), pp.588-591.

Steinigeweg, S.; Gmehling, J., (2003). Esterification of a Fatty Acid by Reactive Distillation. Ind. Eng. Chem. Res., 42, 3612.

Pečar, D. and Goršek, A. (2018). Kinetic modeling of benzoic acid esterification using functionalized silica gel. Chemical Engineering Communications, pp.1-7.

Wajge, R.M. and Reklaitis, G.V., (1999). RBDOPT: a general-purpose object-oriented module for distributed campaign optimization of reactive batch distillation. Chemical Engineering Journal, 75(1), pp.57-68.

Yaws, C.L. (1997). Handbook of Chemical Compound Data for Process Safety. Gulf Professional Publishing.

Zhang, L., Chen, H., Yuan, Y., Wang, S. and Huang, K. (2015). Adopting feed splitting in design of reactive distillation columns with two reactive sections. Chemical Engineering and Processing: Process Intensification, 89, pp.9-18.

\section{Appendix A}

\section{A.1 Mathematical Model for the BRD Operation}

\subsection{Condenser System and Accumulator Tank: $\mathrm{j}=1$}

- Accumulator Tank Mass Balance:

$\frac{d H_{a}}{d t}=L_{D}$

- Component Mass Balance:

a) Distillate Accumulator:

$H_{a} \frac{d x_{a i}}{d t}=L_{D}\left(x_{D i}-x_{a i}\right)$

b) Condenser Holdup Tank: 
$H_{c} \frac{d x_{c i}}{d t}=V_{C} y_{2}-\left(V_{C}+\Delta n_{1} H_{c}\right) x_{D i}+r_{1 i} H_{c}$

- Energy Balance:

$$
0=V_{C} H_{2}^{V}\left(V_{C}+\Delta n_{1} H_{c}\right) H_{1}^{L}-Q_{c}
$$

- Physical Properties and other equations:

$$
\begin{aligned}
H_{1}^{L} & =H_{1}^{L}\left(x_{D 1}, T_{1}, P\right) \\
T_{1} & =T_{1}\left(x_{D 1}, P\right) \\
r_{1 j} & =r_{1 j}\left(k_{e}, x_{D i}\right) \\
\Delta n_{1} & =\sum r_{l j}
\end{aligned}
$$

$L_{l}=R\left(V_{C}+\Delta n_{l} H_{c}\right)$

$L_{D}=(1-R)\left(V_{C}+\Delta n_{1} H_{c}\right)$

\subsection{Internal trays: $\mathrm{j}=2$ to $\mathrm{N}-1$}

- Total Mass Balance:

$0=L_{j-1}+V_{j+1^{-}} L_{j}-V_{j}+\Delta n_{j} H_{j}$

- Component Balance:

$H_{j} \frac{d x_{j}}{d t}=L_{j-1} x_{j-1}+V_{j+1} y_{j+1}-L_{j} x_{j}-V_{j} y_{j}+H_{j} r_{j i}$

- Energy Balance:

$0=L_{j-1} H_{j-1}^{L}+V_{j+1} H_{j+1}^{V}-L_{j} H_{j}^{L}-V_{j} H_{j}^{V}$

- Equilibrium:

$K_{j, i}=\frac{y_{j, i}}{x_{j, i}}$

- Summation:

$\sum y_{j, i}=1$

- Relations Defining Physical Properties and Chemical Reactions:

$K_{j, i}=K_{j, i}\left(y_{j, i}, x_{j, i}, T_{j}, P\right)$

$H_{j, i}^{L}=H_{j, i}^{L}\left(x_{j, i}, T_{j}, P\right)$

$H_{j, i}^{V}=H_{j, i}^{V}\left(y_{j, i}, T_{j}, P\right)$

$r_{j, i}=r_{j, i}\left(k_{e}, x_{j, i}\right)$

$\Delta n_{j}=\sum r_{j, i}$

\subsection{Pot Tank: $\mathrm{j}=\mathbf{N}$}


- Total Mass Balance:

$\frac{d H_{n}}{d t}=L_{n-1}-V_{n}+\Delta n_{n} H_{n}$

- Component Mass Balance:

$$
H_{n} \frac{d x_{n}}{d t}=L_{n-1}\left(x_{n-1}-x_{n}\right)-V_{n}\left(y_{n}-x_{n}\right)+H_{n} r_{n}
$$

- Energy balance:

$$
0=L_{n-1}\left(H_{n-1}^{L}-H_{n}^{L}\right)-V_{n}\left(H_{n}^{V}-H_{n}^{L}\right)+Q_{r}
$$

\section{A.2 Mathematical Model for the sr-BRD Operation}

- Reflux Ratio:

$R=\frac{L_{1}+L_{S}}{V_{C}}$

\subsection{Pot Tank: $\mathrm{j}=\mathrm{N}$}

- Total Mass Balance:

$\frac{d H_{n}}{d t}=L_{n-1}-V_{n}+L_{S}+\Delta n_{n} H_{n}$

- Component Mass Balance:

$H_{n} \frac{d x_{n}}{d t}=L_{n-1}\left(x_{n-1}-x_{n}\right)-V_{n}\left(y_{n}-x_{n}\right)+L_{S}\left(x_{D i^{-}} x_{n}\right)+H_{n} r_{n}$

- Energy balance:

$0=L_{n-1}\left(H_{n-1}^{L}-H_{n}^{L}\right)-V_{n}\left(h_{n}^{V}-H_{n}^{L}\right)+L_{S}\left(H_{1}^{L}-H_{n}^{L}\right)+Q_{r}$ 


\section{Appendix B}

Table B.1 NRTL Binary Parameters for Esterification of Salicylic and Benzoic Acids Systems.

\begin{tabular}{|c|c|c|c|c|}
\hline Component i & Component $\mathrm{j}$ & $\mathrm{A}_{\mathrm{ij}}(\mathrm{cal} / \mathrm{mol})$ & $\mathrm{A}_{\mathrm{ji}}(\mathrm{cal} / \mathrm{mol})$ & $\alpha$ \\
\hline & Methyl & Salicylate & System & \\
\hline ScA & $\mathrm{MeOH}$ & - 272.294 & -209.323 & 0.3 \\
\hline $\mathrm{ScA}$ & $\mathrm{MeSC}$ & -143.808 & 434.917 & 0.3 \\
\hline $\mathrm{MeSC}$ & $\mathrm{MeOH}$ & -376.205 & 698.908 & 0.3 \\
\hline $\mathrm{H}_{2} \mathrm{O}$ & $\mathrm{MeOH}$ & 367.669 & - 112.991 & 0.3 \\
\hline $\mathrm{H}_{2} \mathrm{O}$ & ScA & 1105.54 & - 494.886 & 0.3 \\
\hline $\mathrm{H}_{2} \mathrm{O}$ & $\mathrm{MeSC}$ & 1440.68 & -237.123 & 0.3 \\
\hline & Methyl & Benzoate & System & \\
\hline $\mathrm{BeZ}$ & $\mathrm{MeOH}$ & -330.975 & 529.933 & 0.3 \\
\hline $\mathrm{BeZ}$ & MeBZ & 913.264 & -452.219 & 0.3 \\
\hline MeBZ & $\mathrm{MeOH}$ & 730.217 & 248.007 & 0.3 \\
\hline $\mathrm{H}_{2} \mathrm{O}$ & $\mathrm{MeOH}$ & -231.507 & 738.175 & 0.3 \\
\hline $\mathrm{H}_{2} \mathrm{O}$ & $\mathrm{BeZ}$ & 287.187 & 3231.228 & 0.3 \\
\hline $\mathrm{H}_{2} \mathrm{O}$ & MeBZ & 1232.178 & 3967.954 & 0.3 \\
\hline
\end{tabular}

Table B.2 Antoine Parameters for both (MeBZ, MeSC) systems.

\begin{tabular}{ccccc}
\hline & Methyl & Salicylate & System & \\
\hline Antoine Coefficients & $\mathrm{ScA}$ & $\mathrm{MeOH}$ & $\mathrm{MeSC}$ & $\mathrm{H}_{2} \mathrm{O}$ \\
$\mathrm{A}_{1}[--]$ & 177.3858 & 45.6171 & 202.6840 & 29.8605 \\
$\mathrm{~A}_{2}[\mathrm{~K}]$ & $-1.2871 \mathrm{E}+4$ & $-3.2447 \mathrm{E}+3$ & $-1.2160 \mathrm{E}+4$ & $-3.1522 \mathrm{E}+3$ \\
$\mathrm{~A}_{3}\left[\mathrm{~K}^{-1}\right]$ & $-5.6301 \mathrm{E}+1$ & $-1.3988 \mathrm{E}+1$ & $-6.6670 \mathrm{E}+1$ & -7.3037 \\
$\mathrm{~A}_{4}\left[\mathrm{~K}^{-1}\right]$ & $-1.6667 \mathrm{E}-7$ & $6.6365 \mathrm{E}-3$ & $-1.8009 \mathrm{E}-9$ & $2.4247 \mathrm{E}-9$ \\
$\mathrm{~A}_{5}\left[\mathrm{~K}^{-2}\right]$ & $1.1353 \mathrm{E}-5$ & $-1.0507 \mathrm{E}-13$ & $1.8060 \mathrm{E}-5$ & $1.8090 \mathrm{E}-6$ \\
\hline & Methyl & Benzoate & System & \\
\hline Antoine Coefficients & BeZ & MeOH & MeBZ & $\mathrm{H}_{2} \mathrm{O}$ \\
$\mathrm{A}_{1}[--]$ & -140.0388 & 45.6171 & -13.6342 & 29.8605 \\
$\mathrm{~A}_{2}[\mathrm{~K}]$ & $8.0479 \mathrm{E}+1$ & $-3.2447 \mathrm{E}+3$ & $-2.9133 \mathrm{E}+3$ & $-3.1522 \mathrm{E}+3$ \\
$\mathrm{~A}_{3}\left[\mathrm{~K}^{-1}\right]$ & $6.2611 \mathrm{E}+1$ & $-1.3988 \mathrm{E}+1$ & $1.1773 \mathrm{E}+1$ & -7.3037 \\
$\mathrm{~A}_{4}\left[\mathrm{~K}^{-1}\right]$ & $-6.5321 \mathrm{E}-2$ & $6.6365 \mathrm{E}-3$ & $-2.3979 \mathrm{E}-2$ & $2.4247 \mathrm{E}-9$ \\
$\mathrm{~A}_{5}\left[\mathrm{~K}^{-2}\right]$ & $2.4596 \mathrm{E}-5$ & $-1.0507 \mathrm{E}-13$ & $1.1324 \mathrm{E}-5$ & $1.8090 \mathrm{E}-6$ \\
\hline
\end{tabular}

$\mathrm{A}_{1}, \mathrm{~A}_{2}, \mathrm{~A}_{3}, \mathrm{~A}_{4}, \mathrm{~A}_{5}$ are the regression coeffieicents for each compund 
